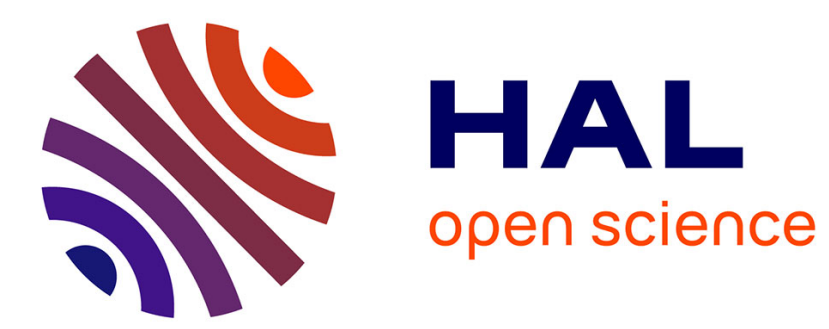

\title{
Welfare Reversals in a Monetary Union
}

Stéphane Auray, Aurélien Eyquem

\section{- To cite this version:}

Stéphane Auray, Aurélien Eyquem. Welfare Reversals in a Monetary Union. 2014. halshs-00925589

\section{HAL Id: halshs-00925589 \\ https://shs.hal.science/halshs-00925589}

Preprint submitted on 8 Jan 2014

HAL is a multi-disciplinary open access archive for the deposit and dissemination of scientific research documents, whether they are published or not. The documents may come from teaching and research institutions in France or abroad, or from public or private research centers.
L'archive ouverte pluridisciplinaire HAL, est destinée au dépôt et à la diffusion de documents scientifiques de niveau recherche, publiés ou non, émanant des établissements d'enseignement et de recherche français ou étrangers, des laboratoires publics ou privés. 
Welfare Reversals in a Monetary Union

Stéphane Auray, Aurélien Eyquem

December 2013 


\section{GATE Groupe d'Analyse et de Théorie Économique Lyon-St Étienne}

93, chemin des Mouilles 69130 Ecully - France

Tel. +33(0)4 72866060

Fax $+33(0) 472866090$

6, rue Basse des Rives 42023 Saint-Etienne cedex 02 - France

Tel. +33 (0)4 77421960

Fax. +33 (0)4 77421950

Messagerie électronique / Email : gate@gate.cnrs.fr

Téléchargement / Download : http://www.gate.cnrs.fr - Publications / Working Papers 


\title{
Welfare Reversals in a Monetary Union*
}

\section{Stéphane Auray ${ }^{\dagger} \quad$ Aurélien Eyquem $\ddagger$}

First version: January 2010

This version: November 2013

\begin{abstract}
We show that welfare can be lower under complete financial markets than under autarky in a monetary union with home bias, sticky prices and asymmetric shocks. Such a monetary union is a second-best environment in which the structure of financial markets affects risk-sharing but also shapes the dynamics of inflation rates and the welfare costs from nominal rigidities. Welfare reversals arise for a variety of empirically plausible degrees of price stickiness when the Marshall-Lerner condition is met. These results carry over a model with active fiscal policies, and hold within a medium-scale model, although to a weaker extent.
\end{abstract}

Keywords: Monetary Union, Financial Markets Incompleteness, Sticky Prices, Fiscal and Monetary Policy.

JEL Class.: E32, E63, F32, F41, F42.

${ }^{*}$ We would like to thank John Leahy, the editor, as well as three anonymous referees for useful comments. We also thank Pierpaolo Benigno, Hafedh Bouakez, Gordon Fisher, Fabio Ghironi, Paul Gomme, Wouter den Haan, Tatyana Koreshkova, Eric Van Wincoop, and conference and seminar participants at several institutions. The traditional disclaimer applies.

${ }^{\dagger}$ CREST-Ensai, Bruz, F-35170, France ; Université du Littoral Côte d'Opale, F-59375 Dunkerque, France ; CIRPEE, Canada. Email: stephane.auray@ensai.fr.

${ }^{\ddagger}$ Corresponding author. Université de Lyon, Lyon, F-69007, France ; CNRS, GATE Lyon Saint-Etienne, Ecully, F-69130, France ; Université Lyon 2, Lyon, F-69007, France. Email: aurelien.eyquem@ens-lyon.fr. 


\section{Introduction}

In this paper, we compare welfare under alternative financial market structures in a monetary union with country-specific shocks, sticky prices, and home bias. What we have in mind is the achievement of monetary unification in Europe, often regarded as part of a process of integrating goods and financial markets. In particular, the integration of financial markets has long been considered to be a crucial condition to foster the adoption of a common currency. The idea dates back to the contributions of Ingram [1969] and Mundell [1973], and places financial markets, and their ability to provide full insurance against country-specific shocks, at the heart of the definition of optimum currency areas. Our main result is that, in a second-best environment such as a monetary union with sticky prices, complete financial markets do not necessarily deliver a higher level of welfare compared to financial autarky. In this environment, complete markets produce welfare gains from risk-sharing compared to financial autarky, but can also generate larger welfare costs from nominal rigidities. This negative effect on welfare can overturn the gains from risk-sharing and invert the usual ranking of welfare. The result holds true for a wide range of empirically plausible parameter values and is robust to various policy configurations. In our view, it relates to and complements the recent results of Farhi and Werning [2013], who show that agents do not acquire the socially optimal level of insurance in a monetary union with sticky prices, even when financial markets are complete.

We lay out a simple two-country model of a monetary union with two goods and sticky prices, following Benigno [2004]. We add home bias in private consumption, as in Pappa and Vassilatos [2007], and consider a non-unitary trade elasticity to analyze the welfare implications of alternative financial markets structures. ${ }^{1}$ In open economy models, complete financial markets allow for international borrowing and risk-sharing among households of different countries. In particular, the real exchange rate moves to ensure the equalization of relative marginal utilities of consumption. Imposing financial autarky introduces a tighter link between income and consumption, i.e. wealth effects, and generally yields welfare losses with respect to perfect risk-sharing. In two-country models with two goods and home bias, when goods are substitutes (respectively complements) in utility, perfect risk-sharing requires larger (resp. smaller) expenditure-switching effects with respect to financial autarky to provide insurance over relative marginal utilities of consumptions, an outcome achieved by having larger (resp. smaller) fluctuations in the real exchange rate (see de Paoli [2009]).

Under flexible exchange rates, with flexible prices or optimal national price stability policies, this result implies that the nominal exchange rate is more (resp. less) volatile under complete markets

\footnotetext{
${ }^{1}$ With a unitary trade elasticity, allocations under different financial market structures coincide. Our analysis therefore has to proceed with a non-unitary trade elasticity.
} 
than under autarky when goods are substitutes (resp. complements) in utility. With a fixed exchange rate or within a monetary union, the volatility pattern applies to the terms of trade, not the nominal exchange rate. When prices are flexible, welfare is not affected by these differences in terms-of-trade volatility. However, when prices are sticky, due to the lack of monetary policy instruments, national inflation rates cannot be fully stabilized. In this second-best environment, alternative financial market structures also shape the welfare costs from nominal rigidities. We show that, when goods are substitutes in utility, i.e. when the trade elasticity is larger than one, equilibria under complete financial markets result in larger variations of terms of trade compared to financial autarky, thus in more volatile national inflation rates, producing larger welfare costs from nominal rigidities. The latter may end-up overturning the welfare gains from a better sharing of risks. We uncover a large set of empirically realistic parameter values that produce welfare reversals, cases where welfare is lower under complete financial markets than under financial autarky. In particular, this is the case when the degree of price stickiness lies in the range of standard empirical estimates and the trade elasticity is above one but not too large.

Extending the baseline model to consider active public spending policies, we also investigate the extent to which the occurrence of welfare reversals can be affected by fiscal policies. ${ }^{2}$ With active fiscal policies and more policy instruments, a monetary union could get closer to a firstbest environment. As in Galí and Monacelli [2008] or Pappa and Vassilatos [2007] however, this is not the case as public spending enters as an argument of the utility function of households. Active fiscal policies require deviations from the efficient provision of public good, creating a trade-off between the benefits from stabilization, and the welfare costs implied by public spending gaps. We show that none of the policy arrangements considered, including a fully optimal - Ramsey policy changes the prediction that welfare reversals can arise for empirically plausible parameter values.

Lastly, we conduct an extensive robustness exercise and compare welfare under complete and incomplete financial markets within a medium-scale model à la Smets and Wouters [2003]. The model includes external habit in consumption, capital accumulation with adjustment costs, a variable utilization rate, sticky prices and sticky wages, as well as price and wage indexation. Our main result is robust to many of the additional assumptions made in the Smets and Wouters [2003] model. However, price indexation, sticky wages, as well as the specific shock structure with high reliance on preference shocks can change our main result. Price indexation lowers the welfare costs from nominal rigidities by reducing producer price dispersion, and increases

\footnotetext{
${ }^{2}$ Our model also shares some of the features of models analyzing the joint design of fiscal and monetary policy in a monetary union, such as Beetsma and Jensen [2005], Ferrero [2009], Galí and Monacelli [2008] and Hjorts $\varnothing$ [2013].
} 
the relative importance of welfare gains from perfect risk-sharing. Wage stickiness significantly lowers the sensitivity of wages and labor supply to fluctuations, and attenuates the strength of cross-country wealth effects. Finally, the overwhelming importance of preference shocks imposed by the Smets and Wouters [2003] framework and calibration affects the welfare ranking of alternative financial market structures. The structure of shocks chosen to represent the business cycle is therefore important in shaping welfare reversal areas.

The paper is structured as follows. Section 2 presents a simple model that is solved analytically to derive qualitative results about the volatility of terms of trade and inflation rates under alternative financial market structures. We also run numerical experiments to assess the extent of welfare reversals depending on key parameter values. Finally, we investigate the robustness of welfare reversals to a variety of stabilization policies. Section 3 questions the sensitivity of welfare reversals to the various assumptions and driving forces considered in a medium-scale monetary union model à la Smets and Wouters [2003]. Section 4 concludes.

\section{A stylized monetary union model}

\subsection{Model highlights}

We lay out a simple model of a monetary union with two regions of identical size, the home country and the foreign country. ${ }^{3}$ In each region there is a representative household maximizing a welfare index that depends on the path of the log of consumption and on the path of hours worked. Optimization gives rise to a labor supply condition and to a standard Euler equation. The structure of financial markets can either consist in complete markets where agents hold a portfolio of Arrow-Debreu securities that are traded before policy choices are made (see Senay and Sutherland $(2007,2011)$ ), producing a state-contingent return and allowing for perfect risksharing, or consist in financial autarky. Under autarky, terms of trade adjust to induce a zero trade balance each period and a zero trade balance condition replaces the risk-sharing condition.

There are two goods in the economy, one produced in each country, made of local varieties. Both goods are imperfectly substitutable with elasticity of substitution $\mu>0$, and households' preferences are biased towards local goods. We denote $(1-\alpha) \in[1 / 2,1]$ as the share of goods produced locally in the consumption bundle of households. In each country there is a unit continuum of firms producing varieties of each type of good with labor using a linear production function affected by exogenous productivity shocks. Price contacts are set according to Calvo [1983], and the law of one price holds. Considering that governments optimally offset steady-state mark-ups and assuming a symmetric degree of price stickiness, the model implies the following

\footnotetext{
${ }^{3}$ The detailed model is described in Appendix A.1.
} 
linearized Phillips curves governing inflation dynamics for Producer Price Indices (PPIs) in each region:

$$
\begin{aligned}
& \widehat{\pi}_{h, t}=\beta E_{t} \widehat{\pi}_{h, t+1}+\kappa\left(\psi \widehat{y}_{t}+\widehat{c}_{t}+\alpha \widehat{s}_{t}-(1+\psi) \widehat{a}_{t}\right) \\
& \widehat{\pi}_{f, t}=\beta E_{t} \widehat{\pi}_{f, t+1}+\kappa\left(\psi \widehat{y}_{t}^{*}+\widehat{c}_{t}^{*}-\alpha \widehat{s}_{t}-(1+\psi) \widehat{a}_{t}^{*}\right)
\end{aligned}
$$

where the term under brackets is the real marginal cost. Labor leisure choices have been used to substitute for real wages and then production functions have been used to eliminate hours worked. In Equations (1)-(2), $\widehat{\pi}_{h, t}=\widehat{p}_{h, t}-\widehat{p}_{h, t-1}$ and $\widehat{\pi}_{f, t}=\widehat{p}_{f, t}-\widehat{p}_{f, t-1}$ are domestic and foreign PPI inflation rates, hats denote the $\log$ of variables and stars characterize foreign variables. Further, $\widehat{y}$ is the $\log$ of output, $\widehat{c}$ is the $\log$ of consumption, $\widehat{s}=\widehat{p}_{f}-\widehat{p}_{h}$ denotes the relative price of the foreign good, i.e. the terms of trade, and $\widehat{a}$ is the log of labor productivity, following an autoregressive process with iid innovations. Further, $\kappa=(1-\eta)(1-\beta \eta) / \eta$ where $\beta$ is the discount factor and $\eta$ the index of price stickiness, $\psi^{-1}$ is the Frisch elasticity on labor supply and $\alpha$ captures the steady-state share of imports in consumption. These Phillips curves are fairly standard, in that a higher degree of price stickiness gives more relative weight to the forward component of inflation, a higher level of output pushes inflation up while higher productivity levels lower inflation. Consumptions appear in the Phillips curves because the marginal utility of consumption affects labor supply. All else equal, a decrease in the marginal utility of consumption lowers labor supply, which exerts an upward pressure on wages, resulting in positive inflation. Finally, terms of trade $\widehat{s}$ play an important role in the dynamics of the model. They appear in Phillips curves because households supply labor based on nominal wages deflated by the Consumption Price Index (CPI) while firms demand labor based on wages deflated by the PPI. These so-called terms-of-trade spillovers on labor supply play an important role, as they are part of the transmission of terms-of-trade fluctuations to inflation rates.

In a monetary union with only one policy instrument, a common central bank can stabilize unionwide inflation but is unable to stabilize relative inflation rates, and cannot implement the flexible price equilibrium (see Benigno [2004]). This policy trade-off is specific to a monetary union with sticky prices and asymmetric shocks, and makes it a second-best environment. Following Benigno [2004], we assume that the central bank follows the optimal monetary policy that fully stabilizes union-wide inflation

$$
\widehat{\pi}_{t}+\widehat{\pi}_{t}^{*}=\widehat{\pi}_{h, t}+\widehat{\pi}_{f, t}=0
$$

and union-wide allocations are just

$$
\widehat{y}_{t}+\widehat{y}_{t}^{*}=\widehat{c}_{t}+\widehat{c}_{t}^{*}=\widehat{a}_{t}+\widehat{a}_{t}^{*}
$$

where we substituted the union-wide goods market clearing condition in the union-wide Phillips curve. This relation holds under both complete asset markets and financial autarky. Hence the 
structure of financial markets affects relative variables only. Further, combining both Phillips curves determines the dynamics of terms of trade through

$$
\widehat{\pi}_{t}^{r}=\beta E_{t} \widehat{\pi}_{t+1}^{r}+\kappa\left(\psi \widehat{y}_{t}^{r}+\widehat{c}_{t}^{r}-2 \alpha \widehat{s}_{t}-(1+\psi) \widehat{a}_{t}^{r}\right)
$$

where $\widehat{x}_{t}^{r}=\widehat{x}_{t}^{*}-\widehat{x}_{t}, \forall x$, and $\widehat{\pi}_{t}^{r}=\widehat{\pi}_{f, t}-\widehat{\pi}_{h, t}=\Delta \widehat{s}_{t}$. Because terms-of-trade movements do not replicate the flexible price equilibrium in a monetary union with asymmetric shocks and sticky prices, we question the impact of alternative financial market structures on welfare. Indeed, alternative financial market structures affect relative allocations and imply different paths for relative prices, i.e. terms of trade. In the presence of nominal rigidities, the structure of financial markets also shapes the dynamics of inflation rates. Under complete markets, real marginal utilities from consumption are equated across countries, periods and states of the world so that agent's relative wealth are insulated from international or country-specific fluctuations. In our framework, the corresponding risk-sharing condition relates terms of trade to relative consumptions according to ${ }^{4}$

$$
\widehat{c}_{t}^{r}=-(1-2 \alpha) \widehat{s}_{t}
$$

Under financial autarky, a zero trade balance condition

$$
\widehat{p}_{h, t}+\widehat{y}_{t}-\widehat{p}_{t}-\widehat{c}_{t}=\widehat{p}_{f, t}+\widehat{y}_{t}^{*}-\widehat{p}_{t}^{*}-\widehat{c}_{t}^{*}=0
$$

is imposed. Combining with goods market clearing conditions

$$
\begin{aligned}
& \widehat{y}_{t}=(1-\alpha) \widehat{c}_{t}+\alpha \widehat{c}_{t}^{*}+2 \mu \alpha(1-\alpha) \widehat{s}_{t} \\
& \widehat{y}_{t}^{*}=(1-\alpha) \widehat{c}_{t}^{*}+\alpha \widehat{c}_{t}-2 \mu \alpha(1-\alpha) \widehat{s}_{t}
\end{aligned}
$$

yields the following relation between relative consumptions and the terms of trade

$$
\widehat{c}_{t}^{r}=-\left(\lambda^{a}-2 \alpha\right) \widehat{s}_{t}
$$

where $\lambda^{a}=1+2(\mu-1)(1-\alpha) .{ }^{5}$ Allocations under both financial market structures coincide exactly when $\mu=1$, as $\lambda^{a}=1$ in this case. When the trade elasticity is unitary, the trade balance is always in equilibrium as movements in imports are offset by equal movements in exports. The open economy under complete markets is thus isomorphic to an open economy with financial autarky. Precisely because of this, we focus on the case of a non-unitary trade elasticity. It is clear from these equations that $\lambda^{a}>1$ whenever $\mu>1$. Hence, for a given variation of terms

\footnotetext{
${ }^{4}$ In the particular case of a separable utility function with log specification for consumption, the risk-sharing condition is $\widehat{p}_{t}+\widehat{c}_{t}=\widehat{p}_{t}^{*}+\widehat{c}_{t}^{*}$, which, after exploiting the definition of CPIs $p_{t}=(1-\alpha) p_{h, t}+\alpha p_{f, t}$ and $p_{t}^{*}=(1-\alpha) p_{f, t}+\alpha p_{h, t}$, and the definition of terms of trade $s_{t}=p_{f, t}-p_{h, t}$, gives Equation (6).

${ }^{5}$ The parameter $\lambda^{a}$ is positive whenever $\mu>\frac{1-2 \alpha}{2(1-\alpha)}$, a condition that we consider as met from now on. The condition is rather loose as it means $\mu>1 / 2$ when the economy is closed and less for an open economy with $\alpha>0$.
} 
of trade, domestic and foreign consumptions will be less synchronized under financial autarky than under complete markets, because the latter are more closely tied to income. A crucial implication is that, when $\mu>1$, the positive cross-country transmission of asymmetric shocks to the consumption of the other country will be larger under complete markets than under financial autarky. However, these different external equilibrium conditions will also result in different general equilibrium dynamics of terms of trade, an issue that we explore extensively in the next paragraphs.

\subsection{Welfare}

We propose a fully micro-founded welfare analysis. In Appendix A.3, we show that a secondorder approximation of the utility function can be used and combined with second-order approximations of equilibrium conditions to derive an accurate measure of welfare within this economy

$$
W_{t} \simeq-\frac{1}{4} E_{t}\left\{\sum_{s=t}^{\infty} \beta^{s-t}\left(\left(\widehat{c}_{s}^{r}-\widetilde{c}_{s}^{r}\right)^{2}+4 \mu \alpha(1-\alpha)\left(\widehat{s}_{s}-\widetilde{s}_{s}\right)^{2}+\psi\left(\widehat{y}_{s}^{r}-\widetilde{y}_{s}^{r}\right)^{2}+\theta \kappa^{-1}\left(\widehat{\pi}_{s}^{r}\right)^{2}\right)\right\}
$$

where tildes refer to the equilibrium under flexible prices and complete financial markets. ${ }^{6}$ First, the derivation of this welfare measure does not make use of financial market conditions. Therefore, this expression is valid to evaluate welfare both under complete markets and financial autarky. However, precisely because gaps and PPI inflation rates will behave differently under alternative financial market structures, welfare levels will differ. Second, because the steady state of our economy is efficient, i.e. steady-state mark-ups are corrected by an optimal subsidy, our welfare measure is purely quadratic. Using a first-order approximation of equilibrium conditions to investigate the dynamics of gaps and inflation rates thus provides an accurate quantification of welfare under alternative financial market structures (see Benigno and Woodford [2012]). ${ }^{7}$ Third, this welfare measure is very close to that derived by Benigno [2004]. Differences arise from the fact that domestic and foreign consumption bundles share the exact same composition in Benigno's framework while they do not in our model, and from the use of the optimal monetary policy of union-wide price stability, that closes union-wide gaps and implies $\widehat{\pi}_{h, t}+\widehat{\pi}_{f, t}=0$, simplifying the way PPI inflation rates affect welfare (the last term in Equation (11)). ${ }^{8}$

\subsection{Equilibria under flexible prices}

Before analyzing equilibria under sticky prices, it is useful to understand how the model behaves under flexible prices. With fully flexible prices the proportion of producers bound to keep prices

\footnotetext{
${ }^{6}$ Terms that depend on exogenous shocks only are ignored. They are irrelevant to rank alternative equilibria in terms of welfare.

${ }^{7}$ Our results are therefore immune to the critique of Kim and Kim [2003].

${ }^{8}$ With identical consumption bundles, we would simply have $\widehat{c}_{t}^{r}=\widetilde{c}_{t}^{r}=0$ and $\widehat{y}_{t}^{r}-\widetilde{y}_{t}^{r}$ would depend on $\widehat{s}_{t}-\widetilde{s}_{t}$ only in our framework, allowing for further simplifications, as in Benigno [2004].
} 
unchanged $(\eta)$ goes to zero, implying that $\kappa \rightarrow \infty$. Phillips curves imply

$$
\psi \widehat{y}_{t}^{r}+\widehat{c}_{t}^{r}-2 \alpha \widehat{s}_{t}-(1+\psi) \widehat{a}_{t}^{r}=0
$$

meaning that real marginal costs are constant. Combining with Equation (6) and Equations (8)-(9), the equilibrium under complete markets and flexible prices is

$$
\begin{aligned}
\widetilde{c}_{t}^{r} & =\frac{(1-2 \alpha)(1+\psi)}{1+\lambda^{c} \psi} \widehat{a}_{t}^{r}=\digamma_{c}^{c} \widehat{a}_{t}^{r} \\
\widetilde{y}_{t}^{r} & =\frac{\lambda^{c}(1+\psi)}{1+\lambda^{c} \psi} \widehat{a}_{t}^{r}=\digamma_{y}^{c} \widehat{a}_{t}^{r} \\
\widetilde{s}_{t} & =-\frac{1+\psi}{1+\lambda^{c} \psi} \widehat{a}_{t}^{r}=\digamma_{s}^{c} \widehat{a}_{t}^{r}
\end{aligned}
$$

where $\lambda^{c}=1+4(\mu-1) \alpha(1-\alpha) \geq 0$. The equilibrium under autarky with flexible prices is derived combining Equation (12) with Equation (10) and Equations (8)-(9):

$$
\begin{aligned}
\widehat{c}_{t}^{r} & =\frac{\lambda^{a}-2 \alpha}{\lambda^{a}} \widehat{a}_{t}^{r}=\digamma_{c}^{a} \widehat{a}_{t}^{r} \\
\widehat{y}_{t}^{r} & =\widehat{a}_{t}^{r}=\digamma_{y}^{a} \widehat{a}_{t}^{r} \\
\widehat{s}_{t} & =-\frac{1}{\lambda^{a}} \widehat{a}_{t}^{r}=\digamma_{s}^{a} \widehat{a}_{t}^{r}
\end{aligned}
$$

where $\lambda^{a}=1+2(\mu-1)(1-\alpha)$. Both equilibria imply qualitatively similar responses to shocks. A positive domestic productivity shock $\left(\widehat{a}_{t}^{r}<0\right)$ increases the relative price of the foreign good $\left(\widehat{s}_{t}>0\right)$, raises domestic production more than foreign production $\left(\widetilde{y}_{t}^{r}<0\right.$ and $\left.\widehat{y}_{t}^{r}<0\right)$ and domestic consumption more than foreign consumption $\left(\widetilde{c}_{t}^{r}<0\right.$ and $\left.\widehat{c}_{t}^{r}<0\right)$.

Quantitatively, equilibria produce different results depending on whether domestic and foreign goods are substitutes or complements in utility, i.e. depending on the value of the trade elasticity $\mu$. First, notice that $\lambda^{a}>\lambda^{c}>1$ when goods are substitutes, i.e. when $\mu>1$, while $\lambda^{a}<\lambda^{c}$ when $\mu<1$. When goods are substitutes $(\mu>1)$, complete markets induce perfect risk-sharing and imply that domestic and foreign consumption are closer than under autarky $\left(\left|\widetilde{c}_{t}^{r}\right|<\left|\widehat{c}_{t}^{r}\right|\right){ }^{9}$ This outcome is achieved by larger movements in terms of trade $\left(\left|\widetilde{s}_{t}\right|>\left|\widehat{s}_{t}\right|\right)$ as, when $\mu>$ 1 , the difference in terms of trade reaction between complete markets and financial autarky $\digamma_{s}^{c}-\digamma_{s}^{a}$ depends on $\lambda^{a}-1+\psi\left(\lambda^{a}-\lambda^{c}\right)=2(\mu-1)(1-\alpha)(1+\psi(1-2 \alpha))$ and is positive when $\mu>1$. Those terms-of-trade movements produce larger expenditure-switching effects, that disconnect domestic and foreign output $\left(\left|\widetilde{y}_{t}^{r}\right|>\left|\widehat{y}_{t}^{r}\right|\right)$. Indeed, the difference in the reaction of relative products between complete markets and financial autarky $\digamma_{y}^{c}-\digamma_{y}^{a}=\left(\lambda^{c}-1\right) /\left(1+\lambda^{c} \psi\right)$ depends on $\lambda^{c}-1$ and is therefore positive when $\mu>1$. These expenditure-switching effects are further reinforced by terms-of-trade spillovers on hours worked especially when the Frisch elasticity $\psi^{-1}$ is high, i.e. when $\psi$ is low, as in this case $\digamma_{y}^{c}-\digamma_{y}^{a}$ is larger.

\footnotetext{
${ }^{9}$ In Appendix A.4, we show that $\digamma_{c}^{c}<\digamma_{c}^{a}$ when $\mu>1$.
} 
Under financial autarky, when $\mu>1$, the zero trade balance condition imposes smaller movements in terms of trade and generates cross-country wealth effects, by which domestic and foreign consumption are more distant. Expenditure-switching effects are thus smaller, and domestic and foreign products evolve more in line than under complete markets. Cross-country wealth effects thus attenuate the effects of terms-of-trade spillovers.

The adjustment pattern is different when goods are complements $(\mu<1)$, as in this case, complete markets induce risk-sharing through smaller movements in terms of trade as compared to the zero trade balance condition: domestic and foreign output are thus closer under complete markets than under autarky, and movements in terms of trade are smaller. Those results are stated more formally in the following proposition.

Proposition 1 With flexible prices, when $\mu>1$, terms of trade and relative outputs are more volatile under complete markets than under autarky, and relative consumptions are less volatile. When $\mu<1$, terms of trade and relative outputs are less volatile under complete markets than under autarky.

Proof. See Appendix A.4.

While these results will prove useful to understand the dynamics with sticky prices, the volatility patterns under flexible prices result in unambiguous welfare effects, as relative inflation rates are unaffected. Indeed, real marginal production costs are constant because any change in the nominal wage is offset by a similar change in the production price. In terms of welfare, price flexibility implies that the weight of $\widehat{\pi}_{t}^{r}$ in Equation (11) goes to zero, so that

$$
W_{t}^{f l e x} \simeq-\frac{1}{4} E_{t}\left\{\sum_{s=t}^{\infty} \beta^{s-t}\left(\left(\widehat{c}_{s}^{r}-\widetilde{c}_{s}^{r}\right)^{2}+4 \mu \alpha(1-\alpha)\left(\widehat{s}_{s}-\widetilde{s}_{s}\right)^{2}+\psi\left(\widehat{y}_{s}^{r}-\widetilde{y}_{s}^{r}\right)^{2}\right)\right\}
$$

By definition of our welfare measure, under complete markets and flexible prices, $W_{t}^{\text {flex,com }}=0$. Hence, deviations from the complete-market equilibrium such as those implied by financial autarky will induce $W_{t}^{f l e x, a u t}<W_{t}^{f l e x, c o m}$. Complete markets thus generate higher levels of welfare compared to financial autarky under flexible prices. The very same outcome could be reached with a flexible nominal exchange rate and two independent optimal monetary policies, as in Benigno [2009]. In this case, we would have $\widehat{\pi}_{h, t}=\widehat{\pi}_{f, t}=\widehat{\pi}_{t}^{r}=0$, and welfare would evolve according to Equation (19) even though $\kappa$ would be positive. With flexible prices or with a flexible exchange rate and optimal national monetary policies, we conclude that complete markets produce a higher level of welfare compared to financial autarky. This conclusion holds true both when goods are substitutes $(\mu>1)$ and complements $(\mu<1)$ in utility. We show in the next paragraph how price stickiness crucially alters this result. 


\subsection{Equilibria under sticky prices}

Contrary to the previous case, as long as prices are sticky within a monetary union with asymmetric shocks, the weight of $\widehat{\pi}_{t}^{r}$ in the welfare measure is non-null and $\widehat{\pi}_{t}^{r}$ can not be equalized to zero through monetary policy. The first-best equilibrium implying $W_{t}=0$ is thus out of reach under both financial market structures. Formally, recalling that $\pi_{t}^{r}=\Delta \widehat{s}_{t}$, and using the relative Phillips curve (5), we can substitute for relative consumptions using Equation (6) under complete markets or Equation (10) under autarky, and substitute for relative productions using relative goods market clearing conditions (Equation (9) minus Equation (8)) to get

$$
\begin{cases}\Delta \widehat{s}_{t}=\beta E_{t} \Delta \widehat{s}_{t+1}+\kappa\left(-\left(1+\lambda^{c} \psi\right) \widehat{s}_{t}-(1+\psi) \widehat{a}_{t}^{r}\right) & \text { under complete markets } \\ \Delta \widehat{s}_{t}=\beta E_{t} \Delta \widehat{s}_{t+1}+\kappa\left(-(1+\psi) \lambda^{a} \widehat{s}_{t}-(1+\psi) \widehat{a}_{t}^{r}\right) & \text { under financial autarky }\end{cases}
$$

The model breaks down to a simple dynamic equation describing the evolution of terms of trade with one lead and one lag. In Appendix A.5, we show that the solution of the this dynamic equation implies

$$
\widehat{s}_{t}=\rho_{1} \widehat{s}_{t-1}-\varphi \widehat{a}_{t}^{r}
$$

where $\varphi=\kappa \rho_{1}(1+\psi) /\left(1-\rho_{2} \rho_{a}\right), \rho_{1}=\left(\left(\delta+\sqrt{\delta^{2}-4 \beta}\right) / 2\right)^{-1}, \rho_{2}=\left(\delta-\sqrt{\delta^{2}-4 \beta}\right) / 2$ and where $\rho_{a}$ is the persistence of the productivity process. The key difference between complete markets and financial autarky lies in the value of $\delta$ as

$$
\delta= \begin{cases}1+\beta+\kappa\left(1+\lambda^{c} \psi\right) & \text { under complete markets } \\ 1+\beta+\kappa(1+\psi) \lambda^{a} & \text { under financial autarky }\end{cases}
$$

This solution allows us to derive some qualitative results about the volatility of terms of trade $\widehat{s}_{t}$ and that of relative inflation rates $\Delta \widehat{s}_{t}$. We already shown that $\lambda^{a}>\lambda^{c}>1$ when goods are substitutes, i.e. when $\mu>1$. As a consequence $\delta$ is smaller under complete markets, making both $\rho_{1}$ and $\rho_{2}$ larger (see Proposition 3 in Appendix A.5.3). As a result the immediate impact of shocks on terms of trade $(\varphi)$ will be larger under complete markets, and the effects will be more persistent as $\rho_{1}$ is larger under complete markets.

Let us focus first on the case of iid shocks, assuming $\rho_{a}=0$. In this case, the variance of terms of trade is

$$
\operatorname{var}\left(\widehat{s}_{t}\right)=\frac{\kappa^{2} \rho_{1}^{2}(1+\psi)^{2}}{1-\rho_{1}^{2}} \operatorname{var}\left(\widehat{a}_{t}^{r}\right)
$$

which, because $\rho_{1}$ is larger under complete markets, implies that terms of trade are more volatile under complete markets when $\mu>1$. In addition, the variance of relative inflation rates

$$
\operatorname{var}\left(\Delta \widehat{s}_{t}\right)=\frac{2 \kappa^{2} \rho_{1}^{2}(1+\psi)^{2}}{1+\rho_{1}} \operatorname{var}\left(\widehat{a}_{t}^{r}\right)
$$


is increasing along with $\rho_{1}$, showing that inflation rates are more volatile under complete markets when $\mu>1 .{ }^{10}$ In the more general case with persistent productivity shocks $\left(\rho_{a}>0\right)$, the variance of terms of trade

$$
\operatorname{var}\left(\widehat{s}_{t}\right)=\frac{\varphi^{2}}{1-\rho_{1}^{2}} \frac{1+\rho_{1} \rho_{a}}{1-\rho_{1} \rho_{a}} \operatorname{var}\left(\widehat{a}_{t}^{r}\right)
$$

is also larger under complete markets than under financial autarky when $\mu>1$ (See Proposition 3 in Appendix A.5.3). Qualitatively, the conclusion reached under flexible prices holds under sticky prices. As already shown by de Paoli [2009], when goods are substitutes $(\mu>1)$ perfect risk-sharing implied by complete financial markets imposes larger variations in the real exchange or relative prices under fixed exchange rates or in a monetary union, as compared to equilibria under financial autarky. As a byproduct, we also show that the variance of relative inflation rates

$$
\operatorname{var}\left(\Delta \widehat{s}_{t}\right)=\frac{\varphi^{2} 2\left(1-\rho_{a}\right)}{1-\rho_{1}^{2}}\left(\frac{1-\rho_{1}}{1-\rho_{1} \rho_{a}}\right) \operatorname{var}\left(\widehat{a}_{t}^{r}\right)
$$

is larger under complete markets than under financial autarky when domestic and foreign goods are substitutes in utility, i.e. when $\mu>1$ (See Proposition 4 in Appendix A.5.3). Given that relative inflation rates are an argument of the welfare function (11), we conclude that complete markets will produce larger welfare losses from nominal rigidities.

Additional intuition can be gained by analyzing the Impulse Response Functions (IRFs hereafter). Figure 1 reports the IRFs under alternative financial market structures after a 1\% positive domestic productivity shock for an illustrative calibration according to which domestic and foreign goods are substitutes. ${ }^{11}$

The pattern uncovered under flexible prices is qualitatively robust under sticky prices, but there are important differences in the magnitude of impulse responses depending on the financial market structure. Under complete markets, cross-country wealth effects are completely offset, as the terms of trade move widely enough to keep relative wealth constant over time. As a consequence, movements in relative consumptions are smaller. Under financial autarky, movements in terms of trade are smaller, and relative consumptions fall more due to cross-country wealth effects. Because prices are sticky, movements in relative inflation rates $\left(\Delta \widehat{s}_{t}\right)$ are also larger under complete markets than under autarky, inducing larger costs from nominal rigidities.

This source of welfare costs can balance and even overturn the welfare gains from a better sharing of risks when $\mu>1$. This point is made clearer when looking at the weights attached to the different components of the welfare measure (11). One the one hand, weights attached

\footnotetext{
${ }^{10}$ It is clear that $\frac{\rho_{1}^{2}}{1+\rho_{1}}$ is an increasing function in $\rho_{1}$.

${ }^{11}$ For an illustrative purpose, we choose the following quarterly calibration: $\beta=0.99, \psi=2, \mu=1.5, \alpha=0.2$, $\eta=0.75, \rho_{a}=0.9, \sigma\left(\varepsilon_{t}^{a}\right)=0.01$, and $\theta=6$.
} 
Figure 1: IRFs after a positive domestic productivity shock when $\mu=1.5$
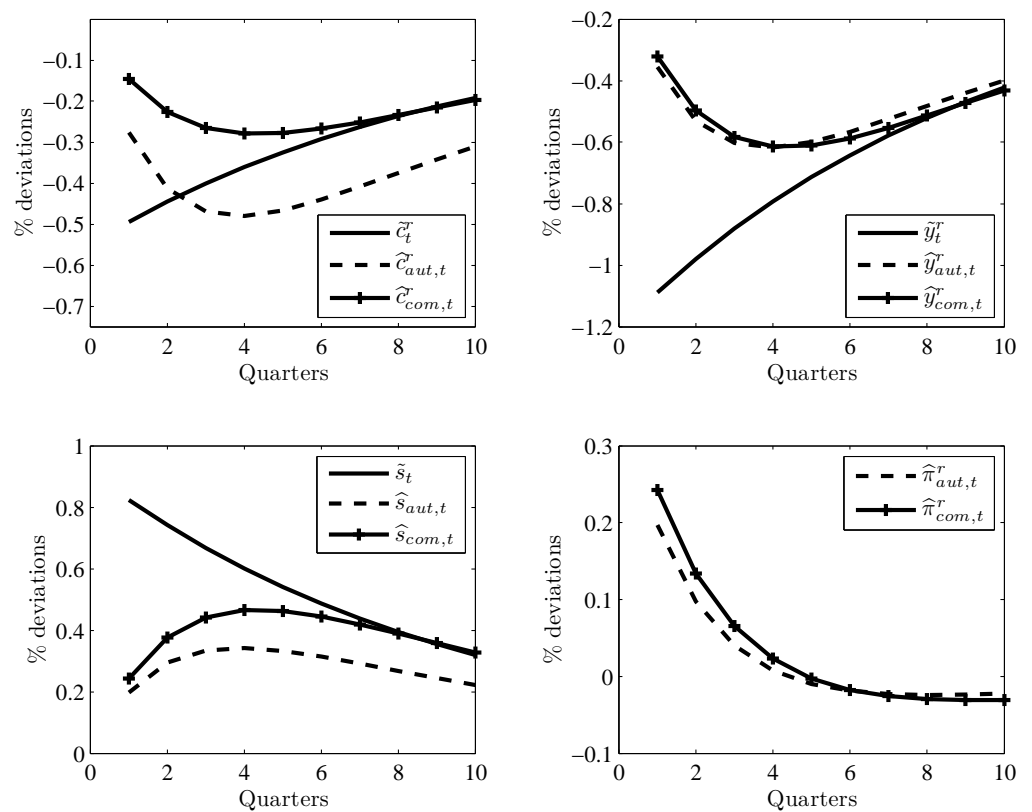

to the gap in relative consumptions, the terms-of-trade gap and the gap in relative outputs are respectively $1, \mu$ and $\psi$. For reasonable calibrations, none of these will be larger than 5 or 10 . On the other hand, the weight of relative inflation rates varies between zero (with flexible prices) and infinity (with fully sticky prices), but for reasonable values of price rigidities $(\eta=0.75$ for instance) with a standard calibrated values of $\theta=6$ and $\beta=0.99$, this weight will be around 70 . Given our qualitative result about the volatility of relative inflation rates, we reach the following conclusions under sticky prices. First, when $\mu<1$, relative inflation rates are less volatile under complete markets, resulting in lower welfare costs from nominal rigidities. Complete markets thus always produce a higher level of welfare compared to financial autarky. Second, when $\mu>1$, relative inflation rates are more volatile under complete markets, resulting in higher welfare costs from nominal rigidities. These costs may overturn the welfare gains from risk-sharing. This is more likely when the degree of price stickiness is large, labor is highly elastic to wages, and the trade elasticity is above one but not too large.

Even though we are able to track analytically the exact expression of welfare as a function of deep parameters, this expression is quite intractable (see Appendix A.6). We thus present quantitative evidence about the interactions of both welfare effects based on numerical experiments. We consider some parameters as fixed, given the consensus about their calibrated value. Adopting a quarterly perspective, the discount factor is $\beta=0.99$. The share of imports in consumption is $\alpha=0.2$, and the elasticity of substitution between varieties $\theta=6$. We then compute the difference in welfare as a function of remaining parameters, the inverse of the Frisch elasticity 
$\psi$, the persistence of productivity shocks $\rho_{a}$, the trade elasticity $\mu$, and the Calvo parameter $\eta$. Figure 2 reports areas of welfare reversals, i.e. areas where welfare is higher under financial autarky than under complete markets, in the $(\eta, \mu)$ space for various combinations of $\left(\psi, \rho_{a}\right)$.

Figure 2: Welfare reversal areas. Shaded areas denote parameterizations for which welfare is higher under financial autarky than under complete markets.
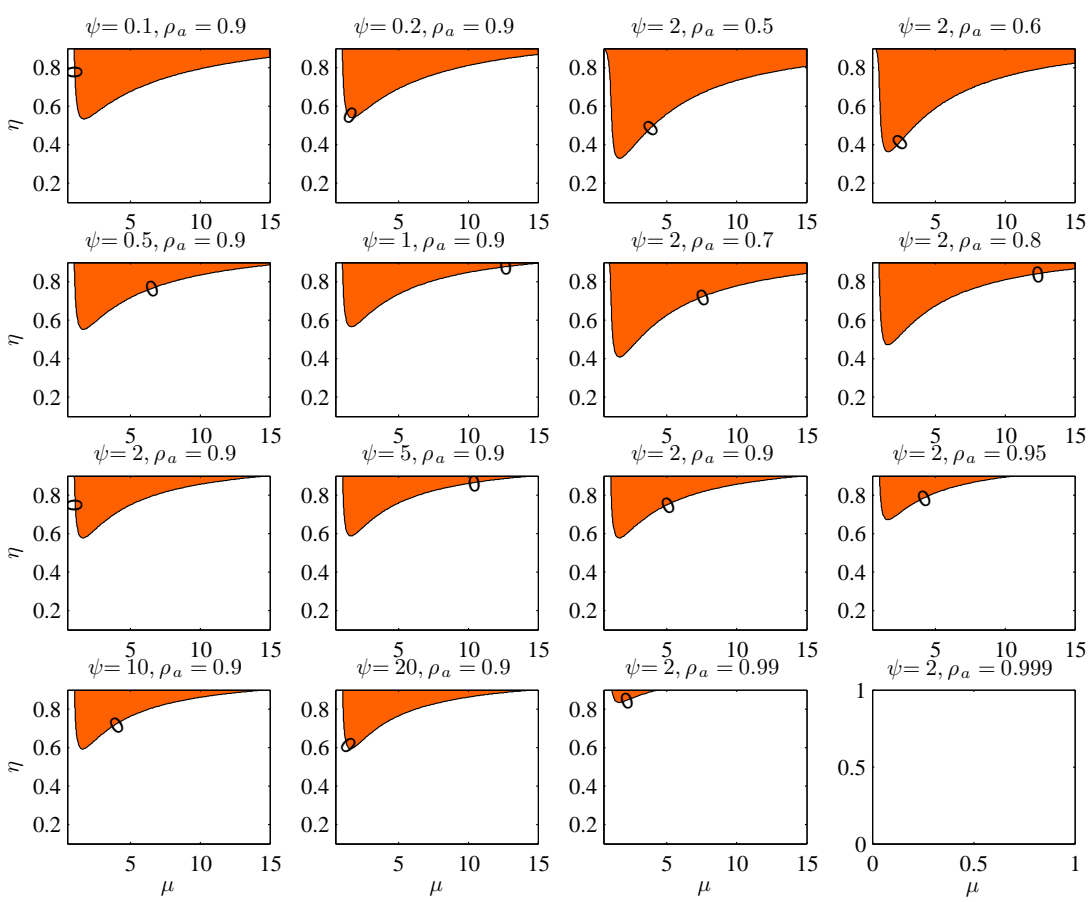

Figure 2 confirms that there is no welfare reversal when domestic and foreign goods are complements in utility, i.e. when $\mu<1$. Further, as long as domestic and foreign goods are substitutes $(\mu>1)$, for a given value of the trade elasticity, welfare reversals occur when prices are stickier. Stickier prices raise the volatility of relative inflation rates and magnify their weight in the welfare measure, which enhances the probability of a welfare reversal. However, the larger the trade elasticity $\mu$, the larger the price stickiness parameter needs to be to produce a welfare reversal. This is the case for two reasons. First, larger values of $\mu$ reduce the size of terms-of-trade movements required to reach the external equilibrium under both financial market structures, as they strengthen the magnitude of expenditure-switching effects for a given degree of price stickiness. The volatility of relative inflation rates, and therefore the welfare costs of nominal rigidities, are thus dampened under both financial market structures. Second, larger values of $\mu$ increase the weight of the terms-of-trade gap in the welfare function relative to the weight of relative inflation rates.

Figure 2 also shows that the Frisch elasticity $\psi^{-1}$ affects reversal areas. When labor supply is 
more responsive, i.e. when $\psi$ is low, the impact of expenditure-switching on output is magnified, and differences in the dynamics of real marginal costs and inflation rates are larger. In addition, the weight of the gap in relative outputs in the welfare measure falls relative to the weight of relative inflation rates. Welfare reversal areas are thus wider when $\psi$ is small.

Finally, the persistence of shocks also shapes welfare reversal areas. On the one hand, persistence downplays the importance of nominal rigidities in the adjustment process and magnifies the importance of allocation effects. As already shown by Baxter and Crucini [1995] and Chari, Kehoe and McGrattan [2002], the difference in real allocations resulting from alternative financial market structures is larger when shocks are close-to-permanent. Welfare gains from risk-sharing are thus more likely to be large. On the other hand, more persistent shocks imply less consumption smoothing and larger movements in terms of trade, potentially raising the difference in welfare costs from nominal rigidities. As a result of those opposite effects, persistence affects the difference in welfare in a non-linear way. It increases the probability of a welfare reversal for intermediate to large values of persistence, and then decreases the probability for close-to-permanent shocks (see Figure 4 in Appendix A.7).

\subsection{Sensitivity to the policy set-up}

In the previous section, we consider a very simple case where monetary policy fully stabilizes union-wide inflation, abstracting from any kind of fiscal policy. We now investigate the occurrence of welfare reversals under a variety of policy arrangements. For the purpose, we incorporate public spending in the utility function to the baseline model and consider alternative combinations of monetary and fiscal policies. Lifetime welfare is now

$$
E_{t}\left\{\sum_{s=t}^{\infty} \beta^{s-t}\left((1-\varrho) \log c_{s}+\varrho \log g_{s}-\chi \frac{n_{s}^{1+\psi}}{1+\psi}\right)\right\}, 0<\varrho<1
$$

where $g_{t}$ is the amount of public expenditure falling on goods produced locally. The decentralized equilibrium is now characterized by the following government budget constraints and goods market clearing conditions ${ }^{12}$

$$
\begin{aligned}
& g_{t}=\operatorname{tax}_{t}+\tau \int_{0}^{1} p_{h, t}(\omega) y_{t}(\omega) \\
& y_{t}=(1-\alpha)\left(\frac{p_{h, t}}{p_{t}}\right)^{-\mu} c_{t}+\alpha\left(\frac{p_{h, t}}{p_{t}^{*}}\right)^{-\mu} c_{t}^{*}+g_{t}
\end{aligned}
$$

It is clear from the modified utility function that the efficient steady-state provision of public goods will be $g=\varrho y$. In the following policy exercise, the decentralized steady state is thus

\footnotetext{
${ }^{12}$ Similar conditions hold in the foreign economy.
} 
consistent with the central planner steady state. All equilibria considered in this section share the same steady state, and welfare differences relate to business cycle properties only.

We consider the following alternative policy set-ups. First, we compute Ramsey equilibria. ${ }^{13}$ Second, we consider the following monetary policy rule for the central bank of the monetary union

$$
\frac{r_{t}}{r}=\left(\frac{r_{t-1}}{r}\right)^{d_{r}}\left(\left(\frac{\pi_{t}^{u}}{\pi^{u}}\right)^{d_{\pi}^{r}}\left(\frac{y_{t}^{u}}{\widetilde{y}_{t}^{u}}\right)^{d_{y}^{r}}\right)^{1-d_{r}}
$$

where $y_{t}^{u}=\left(y_{t}\right)^{1 / 2}\left(y_{t}^{*}\right)^{1 / 2}$ is the union-wide output and $\widetilde{y}_{t}^{u}$ its flexible prices equilibrium value. Following the vast literature on fiscal rules, we consider the following fiscal policy rule for the domestic government ${ }^{14}$

$$
\frac{g_{t}}{g}=\left(\frac{g_{t-1}}{g}\right)^{d_{g}}\left(\left(\frac{y_{t}}{\widetilde{y}_{t}}\right)^{d_{y}^{g}}\right)^{1-d_{g}}
$$

and a symmetric rule for the foreign government.

We focus on the following cases: (A) active monetary policy and passive fiscal policy $\left(g_{t}=g\right)$ with (A-I) optimized Taylor coefficients and (A-II) non-optimized Taylor coefficients, and (B) active monetary policy with non-optimized coefficients and active fiscal policy with (B-I) optimized coefficients on domestic output and (B-II) non-optimized coefficients on domestic output. We calibrate the model in the following way. The discount factor is $\beta=0.99$. Following the literature reporting low values of the Frisch elasticity, we set $\psi=2$. We set the share of public expenditure in GDP to $\varrho=0.22$. Following Backus, Kehoe and Kydland [1993], the trade elasticity is $\mu=1.5$. Using data on intra-zone trade flows for the Euro area, we set the share of imports in consumption to $\alpha=0.2$. Evidence by Rumler [2007] suggests that the Calvo parameter on price adjustment is $\eta=0.75$. The elasticity of substitution between varieties is $\theta=6$. Finally, the productivity shock has a persistence $\rho_{a}=0.9$ and the standard deviation of innovations is $\sigma\left(\varepsilon_{t}^{a}\right)=0.00628$. Table 1 reports the results in terms of welfare and volatility under the alternative policy scenarios. The welfare analysis consists in the total welfare losses from business cycles $\mathcal{L}=100\left(E\left(W_{t}\right)-W\right) /\left(c+c^{*}\right)$ and the welfare difference between autarky and complete financial markets $\mathcal{W}=100\left(E\left(W_{t}^{\text {aut }}\right)-E\left(W_{t}^{\text {com }}\right)\right) /\left(c+c^{*}\right)$.

\footnotetext{
${ }^{13}$ Under a full Ramsey policy, the central planner jointly determines and implements the optimal public spending and monetary policies so as to maximize the aggregate welfare within the monetary union subject to the set of equilibrium conditions. As Ramsey policies are typically known to be time-inconsistent, we adopt the timeless perspective (see Woodford [1999] and Giannoni and Woodford [2002]). More precisely, we assume that optimal conditions at time zero are set consistently with a previous commitment, such as the one described by optimal conditions between period $t$ and $t+1$. We solve for Ramsey policies using the "get_ramsey" procedure developed by López-Salido and Levin [2004] and used in Levin, Onatski, Williams and Williams [2006]. We simulate the model with a second-order approximation to the optimal conditions using Dynare (http://www.dynare.org/).

${ }^{14}$ See Beetsma and Jensen [2005], Ferrero [2009], Galí and Monacelli [2008], Kirsanova, Satchi, Vines and WrenLewis [2007], Kirsanova and Wren-Lewis [2012] and Pappa and Vassilatos [2007] among others for theoretical contributions, and Candelon, Muysken and Vermeulen [2010], Fatás and Mihov [2003], Galí and Perotti [2003] and Wyplosz [2002] among others for empirical contributions.
} 
Table 1: Standard deviations and welfare

\begin{tabular}{|c|c|c|c|c|c|}
\hline & \multicolumn{5}{|c|}{ Financial autarky } \\
\hline & \multicolumn{2}{|c|}{$\mathrm{A}$} & \multicolumn{2}{|c|}{$\mathrm{B}$} & Ramsey \\
\hline & $\mathrm{I}$ & II & $\mathrm{I}$ & II & \\
\hline$\sigma(y)$ & 1.3665 & 1.2121 & 1.4379 & 1.5608 & 1.3906 \\
\hline$\sigma(c)$ & 1.6389 & 1.4227 & 1.3894 & 1.0198 & 1.1919 \\
\hline$\sigma(g)$ & - & - & 1.3189 & 3.7053 & 1.9679 \\
\hline$\sigma(n)$ & 0.3599 & 0.3537 & 0.3355 & 0.3927 & 0.1239 \\
\hline$\sigma\left(\pi_{i}\right)$ & 0.4196 & 0.1374 & 0.3396 & 0.1983 & 0.0988 \\
\hline$\sigma(s)$ & 1.1054 & 1.1053 & 0.9967 & 0.7825 & 0.8838 \\
\hline$d_{r}$ & 0.7000 & $0.0473^{*}$ & 0.7000 & 0.7000 & - \\
\hline$d_{\pi}^{r}$ & 1.5000 & $99661^{*}$ & 1.5000 & 1.5000 & - \\
\hline$d_{y}^{r}$ & 0.1250 & $0.0255^{*}$ & 0.1250 & 0.1250 & - \\
\hline$d_{g}$ & - & - & 0.7000 & $0.8959^{*}$ & - \\
\hline$d_{y}^{g}$ & - & - & -0.5000 & $-2.5540^{*}$ & - \\
\hline \multirow[t]{2}{*}{$\mathcal{L}^{g}(\%)$} & 8.5142 & 1.3294 & 5.3997 & 2.8919 & 0.5909 \\
\hline & \multicolumn{5}{|c|}{ Complete financial markets } \\
\hline$\sigma(y)$ & 1.3977 & 1.2394 & 1.4526 & 1.5672 & 1.4323 \\
\hline$\sigma(c)$ & 1.5293 & 1.2856 & 1.2921 & 0.9037 & 1.0836 \\
\hline$\sigma(g)$ & - & - & 1.2103 & 3.6413 & 2.2322 \\
\hline$\sigma(n)$ & 0.3771 & 0.3638 & 0.3658 & 0.4213 & 0.1205 \\
\hline$\sigma\left(\pi_{i}\right)$ & 0.4287 & 0.1798 & 0.3510 & 0.2013 & 0.1214 \\
\hline$\sigma(s)$ & 1.5884 & 1.5884 & 1.4991 & 1.2395 & 1.2307 \\
\hline$d_{r}$ & 0.7000 & $0.0000^{*}$ & 0.7000 & 0.7000 & - \\
\hline$d_{\pi}^{r}$ & 1.5000 & $2.9700^{*}$ & 1.5000 & 1.5000 & - \\
\hline$d_{y}^{r}$ & 0.1250 & $0.0359^{*}$ & 0.1250 & 0.1250 & - \\
\hline$d_{g}$ & - & - & 0.7000 & $0.8968^{*}$ & - \\
\hline$d_{y}^{g}$ & - & - & -0.5000 & $-2.9698^{*}$ & - \\
\hline \multirow[t]{2}{*}{$\mathcal{L}^{g}(\%)$} & 8.9737 & 1.8905 & 5.9013 & 3.1021 & 0.8647 \\
\hline & \multicolumn{5}{|c|}{ Welfare difference } \\
\hline $\mathcal{W}(\%)$ & 0.4594 & 0.5611 & 0.5016 & 0.2102 & 0.2738 \\
\hline
\end{tabular}

* : Optimized coefficients. A-I: Passive fiscal policy and active monetary policy with non-optimized coefficients. A-II: Passive fiscal policy and active monetary policy with optimized coefficients. B-I: Active monetary policy with non-optimized coefficients and active fiscal policy and with non-optimized coefficients. B-II: Active monetary policy with nonoptimized coefficients and active fiscal policy and with optimized coefficients. 
Table 1 reports the expected ranking of policies in terms of welfare losses from fluctuations. Obviously, full Ramsey policies deliver the lowest welfare losses (last column). A set-up with passive fiscal policy and active monetary policy with non-optimized coefficients yields the largest welfare losses from fluctuations (first column). Adding active fiscal policies lowers welfare losses by a substantial amount, especially with optimized public spending rules (fourth column). Among set-ups with policy rules, a set-up with an optimized monetary policy rule and passive fiscal policy delivers the lowest level of welfare losses (second column). The high ranking of union-wide price stability policies points to the large contribution of the volatility of inflation rates in the welfare loss function, as seen in the previous section. In addition, the ranking of welfare losses follows closely the ranking of producer price inflation volatility.

Given the value of optimized coefficients, the optimal monetary policy consists in stabilizing union-wide inflation. Because the union-wide output gap is strictly tied to the union-wide inflation rate when the business cycle is driven by productivity shocks only, this policy also closes the union-wide output gap. In other words there is no trade-off in policy objectives from a union-wide perspective, consistently with Galí and Monacelli [2008]. Optimized fiscal policies are counter-cyclical with respect to output gaps, seek to close national gaps, and feature a large persistence term. However, contrary to the case of monetary policy, there is a trade-off between the strength of fiscal stabilization and the associated welfare costs. Indeed, as public expenditure enters the utility function of households, deviations from the efficient provision of public goods implied by stabilization policies also incur some welfare costs. This trade-off is mostly apparent when comparing the volatility of public expenditure under optimized fiscal rules and under the Ramsey policy.

Under all policy arrangements, a regular pattern governs the volatility of key variables under alternative financial markets. Output, PPI inflation rates and terms of trade are always more volatile under complete markets than under financial autarky. Under all set-ups except under Ramsey policies, hours are also more volatile under complete financial markets. Private consumptions on the other hand are always less volatile under complete markets. Hence, none of the policies considered in Table 1 reverse the mechanism highlighted in the previous section, according to which complete markets produce a lower level of welfare than financial autarky.

Another noticeable result is that a more efficient monetary policy (optimized vs. non-optimized) magnifies the welfare difference between both financial market structures, while more efficient fiscal policies (optimized vs. non-optimized) reduce the welfare difference for a given monetary policy. This highlights the essential role played by monetary and fiscal policies in shaping the extent of business cycle asymmetries within the monetary union. A more efficient monetary policy is beneficial in the sense that the volatility of union-wide inflation is brought down, but 
at the same time contributes to the increase in national inflation rate asymmetries. Fiscal policies are more efficient in handling asymmetries but are insufficient to prevent welfare reversals, due to the trade-off between the costs and benefits of stabilization. Overall, Table 1 shows that welfare reversals arise for a wide range of stabilization policies, regardless of their efficiency in stabilizing the economy.

\section{A medium-scale monetary union model}

We now investigate the welfare difference implied by alternative financial markets structures in a richer two-country model à la Smets and Wouters [2003]. The latter embeds additional frictions such as sticky wages, capital accumulation with investment adjustment costs, variable capacity utilization, external habits in consumption and a much wider set of shocks, including productivity shocks, investment shocks, mark-up shocks, public spending shocks, preference shocks, monetary policy and inflation target shocks. In addition, we consider incomplete markets with portfolio adjustment costs rather than financial autarky as the alternative to complete markets, as this assumption is a more realistic description of adjustments in international financial markets. The full model is described in Appendix B.1, and equilibrium conditions in level are solved using a second-order approximation. ${ }^{15}$ This approach allows us to evaluate the welfare losses from fluctuations under alternative financial markets structures, as unconditional means differ from steady-state values through the impact of second-order moments on first-order moments. Alternatively, using a first-order approximation would require the derivation of an exact expression of welfare using second-order approximations of equilibrium conditions, which is out of reach given the dimension of the model.

\subsection{Calibration}

The model is calibrated to the closed economy version of the Euro Area model of Smets and Wouters [2003]. We consider a symmetric calibration across countries in the baseline case, and purely asymmetric shocks. Steady-state mark-ups are assumed to be corrected by appropriate subsidies. Further, following Pappa and Vassilatos [2007], we set the share of imports to $\alpha=0.2$. The value of $\mu$ is widely debated in the literature. The range of empirical estimates is typically very large and includes values as low as 0.43 (see Lubik and Schorfheide [2006]), as well as values as large as 4 or 6 (see Broda and Weinstein [2006]) or more (see Harrigan [1993]). The literature on international business cycles usually sets this parameter to intermediate values to match the volatility of the trade balance (see Backus et al. [1993]). Following this literature, we set $\mu=1.5$, and present an extensive sensitivity analysis with respect to this parameter. Table 3 in Appendix B.3 reports the baseline parameter values. Alternative calibrations could

\footnotetext{
${ }^{15}$ We use the Dynare routine.
} 
follow Pytlarczyk [2005] or de Walque, Smets and Wouters [2005]. However, those work produce quite different estimates for structural parameters and imply different patterns of international spillovers. This lack of consensus for the Euro Area suggests that medium-scale models may not produce a reliable representation of the business cycle, and that the implied predictions should be interpreted with caution.

\subsection{Welfare}

Table 2 reports the difference in welfare expressed as a percentage of steady-state current consumption $\mathcal{W}=100\left(E\left(W_{t}^{i n c}\right)-E\left(W_{t}^{c o m}\right)\right) /\left(c+c^{*}\right)$ for different model specifications and for a variety of shocks.

Table 2: Difference in welfare between incomplete and complete financial markets, in $\%$ of steady-state consumption

\begin{tabular}{|c|c|c|c|c|c|c|c|}
\hline & $\begin{array}{c}\text { Prod. } \\
\sigma_{a}\end{array}$ & $\begin{array}{c}\text { Pref. } \\
\sigma_{b}+\sigma_{n}\end{array}$ & $\begin{array}{c}\text { Pub. } \\
\sigma_{g}\end{array}$ & $\begin{array}{c}\text { Mk-up } \\
\sigma_{w}+\sigma_{p}\end{array}$ & $\begin{array}{c}\text { Invt. } \\
\sigma_{i}\end{array}$ & $\begin{array}{c}\text { All } \\
-\end{array}$ & $\begin{array}{c}\text { No Pref. } \\
-\end{array}$ \\
\hline I & 0.0473 & 0.4845 & 0.0014 & -0.0000 & - & 0.5332 & 0.0486 \\
\hline II: I + indexation & -0.0046 & -0.5829 & -0.0079 & 0.0000 & - & -0.5954 & -0.0125 \\
\hline III: I + sticky wages & 0.0212 & -0.2328 & -0.0006 & 0.0000 & - & -0.2122 & 0.0206 \\
\hline I + habit & 0.1334 & 1.3782 & 0.0013 & 0.0000 & - & 1.5128 & 0.1347 \\
\hline$I+$ capital & 0.0538 & 0.2389 & 0.0037 & -0.0000 & 0.0002 & 0.2966 & 0.0577 \\
\hline IV $:$ I + habit + capital & 0.1375 & 0.6149 & 0.0056 & 0.0000 & 0.0004 & 0.7585 & 0.1436 \\
\hline V: Full model & -0.0447 & -0.7511 & -0.0364 & -0.0001 & -0.0085 & -0.8407 & -0.0896 \\
\hline $\mathrm{V}-$ indexation $\left(\gamma^{w}=\gamma^{p}=0\right)$ & 0.0490 & -0.3876 & -0.0039 & 0.0000 & -0.0005 & -0.3429 & 0.0447 \\
\hline
\end{tabular}

Model I is the closest to the simple model presented in the previous section. We start from this model and look at how the different assumptions considered in the medium-scale model affect the probability of a welfare reversal. Model I predicts a moderate welfare reversal under all driving forces of the business cycle, except for mark-up shocks, but the latter account for a very low share of the variance of key variables.

Model II introduces price indexation, and changes the previous result, as the model with complete markets produces a higher level of welfare. Price indexation cuts the volatility of price inflation rates, and reduces the dispersion of PPIs, thereby moderating the welfare costs from nominal rigidities under both financial market structures. The cut is large enough to let the welfare gains from risk-sharing under complete markets outweigh the larger costs from nominal rigidities.

Model III is the baseline model of Section 2 augmented with sticky wages. In this case again, when all shocks are considered together, complete markets dominate. The reason is that wage stickiness reduces the size of cross-country wealth effects by partially muting the impact response of labor supply. This in turn favors the model with complete markets in terms of welfare 
with respect to the model with incomplete markets. This effect also lowers the domination of the incomplete market model with productivity shocks only, but essentially changes the welfare ranking with preference shocks only. When all shocks are considered, the welfare ranking induced by preference shocks dominates, and complete markets produce welfare gains. This result highlights the overwhelming importance of preference shocks in the variance decomposition of key variables in Model III, including welfare. ${ }^{16}$ As shown in Table 2, removing those shocks and leaving productivity shocks be the main driver of the business cycle changes the prediction of Model III, as the model with incomplete markets dominates in terms of welfare. An important conclusion is that welfare reversals are quite sensitive to the shock structure chosen to represent the business cycle.

Adding capital accumulation, habit persistence, or both as in model IV, does not change the prediction of model I. Finally, considering the full model (model V), complete markets produce a higher level of welfare compared to incomplete markets. The result is robust to removing preference shocks.

Those results show the high sensitivity of welfare reversals to the size of the welfare costs from nominal rigidities and to the strength of cross-country wealth effects. Any mechanism reducing the welfare costs from price stickiness, as indexation, or attenuating the strength of cross-country wealth effects, as wage stickiness, contributes to lower the probability of a welfare reversal. Further, capital accumulation and external habit formation do not change qualitatively the prediction of the stylized model. From a quantitative perspective, however, the former dampens and the latter magnifies the welfare difference between equilibria under complete and incomplete financial markets. Lastly, our results suggest that welfare reversals are sensitive to the structure and calibration of shocks driving the business cycle.

Quantitatively, differences in welfare losses from fluctuations are quite small in absolute terms, but rather important relative to the total welfare losses from business cycles. In the full model (model V), the total losses from fluctuations represent $2.91 \%$ of steady-state consumption, or equivalently $0.0291 \%$ of permanent steady-state consumption, a measure that is consistent with Lucas [2003]. The welfare difference between complete and incomplete markets is $0.84 \%$ of steady-state consumption in favor of the complete market equilibrium, which represents about $30 \%$ of total welfare losses. Hence, even though figures reported in Table 2 seem small, they represent a non-negligible share of the welfare losses from fluctuations.

\footnotetext{
${ }^{16}$ As shown in Appendix B.4, with the standard Smets and Wouters [2003] calibration, after removing the contribution of monetary shocks, preference shocks account for $94 \%$ of the variance of output, $95 \%$ of the variance of consumption, $70 \%$ of the variance of hours, $82 \%$ of the variance of PPI inflation rates and $97 \%$ of the variance of welfare.
} 


\subsection{Sensitivity Analysis}

We now conduct a sensitivity analysis with respect to key parameters. While the response of monetary policy to the union-wide inflation rate has negligible effects on the occurrence of welfare reversals, the trade openness parameter $\alpha$ and the cross-country correlation of shocks both reduce the welfare difference between equilibria under complete and incomplete markets, by making the monetary union more homogeneous. ${ }^{17}$ When the share of imports increases, asymmetric shocks are more powerfully transmitted to the rest of the monetary union through trade in consumption and capital goods, making the business cycle more synchronized among union's members, and risk-sharing through financial markets less relevant for households' welfare. Similarly, when the correlation of shocks increases, welfare differences are attenuated, and simply vanish when shocks are perfectly correlated. In this case, the monetary union and member countries behave as a single closed economy where the structure of financial markets is irrelevant for welfare.

Figure 3 reports the sensitivity of $\mathcal{W}$ to changes in the value of the trade elasticity $\mu$, the level of the Calvo parameters on prices $\eta^{p}$ and wages $\eta^{w}$, and the degree of heterogeneity in Calvo price contracts $\Omega .^{18}$

Figure 3: Sensitivity of $\mathcal{W}$ to changes in key parameters of the model.
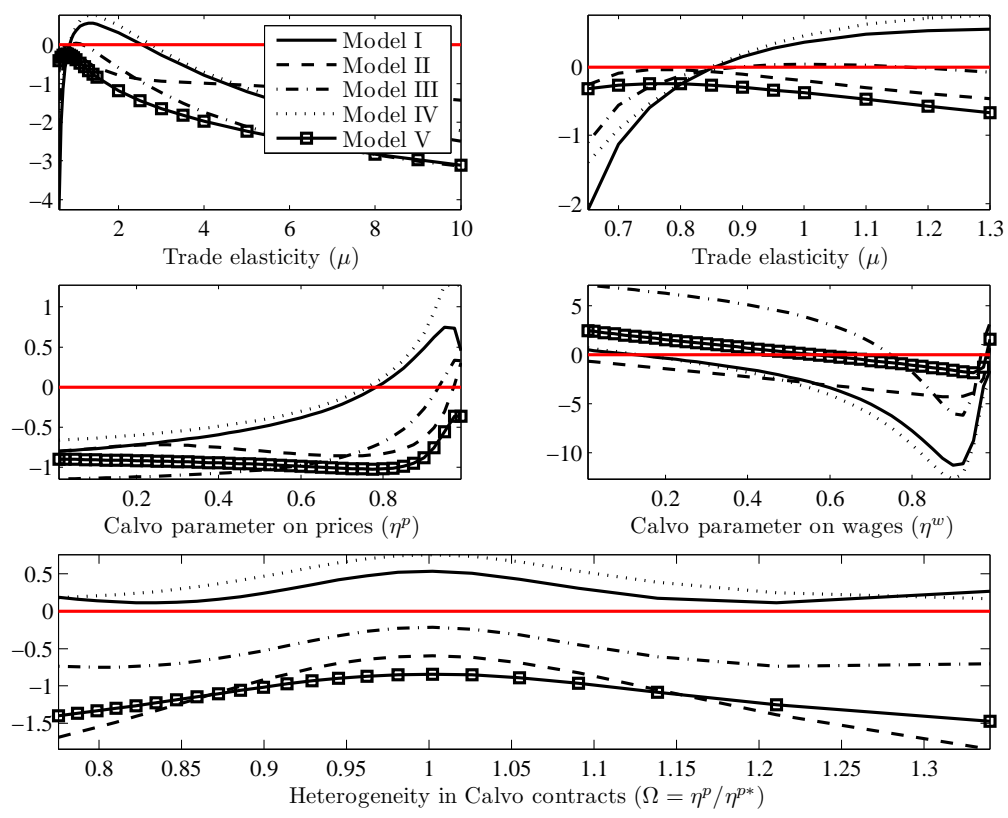

\footnotetext{
${ }^{17}$ Those results are not reported but available upon request.

${ }^{18}$ Heterogeneity in Calvo contracts is considered as in Benigno [2004], assuming that the average duration of price contracts remains constant and equal to its calibrated value but results from heterogeneous durations across the monetary union. More precisely, we assume $\left(1-\eta^{p}\right)^{-1 / 2}\left(1-\eta^{p *}\right)^{-1 / 2}=\left(1-\bar{\eta}^{p}\right)^{-1}$, vary $\eta^{p}$ and report the results as a function of $\Omega=\eta^{p} / \eta^{p *}$.
} 
The trade elasticity is a crucial parameter for the welfare ranking of alternative financial markets. Model I, the baseline model, and model IV, that imbeds capital accumulation and external habit in consumption, behave very similarly, as equilibria under complete markets welfare-dominate for low values of the trade elasticity, are dominated for intermediate values, between 0.85 and 2.5 , and dominate again for large values of the trade elasticity. This pattern is virtually identical to that uncovered in the previous section, except that the threshold for the trade elasticity is now less than one, because the zero trade balance condition depends on additional parameters. Model II, with indexation, and model V, the full Smets and Wouters [2003] model, insensitively predict that complete markets deliver higher levels of welfare. Finally, model III predicts a small welfare reversal for a very narrow interval of the trade elasticity, between 0.95-1.15.

Model I, III and IV produce a strictly increasing relation between the difference in welfare and the Calvo parameter on producer prices $\eta^{p}$. The introduction of indexation in model II and V produces a slightly different pattern, as the relation is flat or decreasing for low values of $\eta^{p}$ and then increasing for larger values. In all cases but the full model (model V), there exists a value of $\eta^{p}$ that is large enough to produce a welfare reversal, even though this value is empirically unrealistic for model III and model IV.

The degree of wage rigidity $\left(\eta^{w}\right)$ exerts a negative effect on the occurrence of welfare reversals for all models as long as $\eta^{p}<0.9$. This can easily be understood as a higher degree of wage rigidity de-emphasizes the importance of cross-country wealth effects. More generally, welfare reversals are directly related to the strength of the wealth effects generated under incomplete financial markets. Hence, any mechanism altering the transmission of expenditure-switching effects to labor supply and output, such as the mechanism proposed by Galí [2011] or Greenwood, Hercowitz and Huffman [1988] preferences could change the ranking of alternative financial market structures. When $\eta^{p}>0.9$, however, welfare reversals arise as wage stickiness indirectly participates to the stickiness of terms of trade, through their impact on relative marginal costs. With highly sticky wages, this effect is large enough to counterbalance the negative impact on cross-country wealth effects.

Finally, heterogeneity in Calvo price contracts $\Omega$ alters the magnitude of welfare difference but does not change welfare reversal patterns.

\section{Conclusion}

A two-country monetary union with home bias, sticky prices and country-specific shocks is a second-best environment. A central bank can not close all gaps and replicate the flexible prices equilibrium. National inflation rates are thus different from zero, and the dynamics of relative prices is different from its flexible prices dynamics. Alternative financial market structures, as 
they alter the dynamics of relative prices, also affect the dynamics of national inflation rates, and shape the welfare costs from nominal rigidities.

In this paper, we have shown that complete financial markets, while they produce welfare gains through perfect risk-sharing compared to incomplete markets, can also bring welfare costs by increasing the volatility of inflation rates when the Marshall-Lerner condition on the trade balance is met. The value of the trade elasticity and the degree of price stickiness are crucial to determine the extent of what we have called welfare reversals. The value of the Frisch elasticity on labor supply and the persistence of shocks are also very important, as they affect the magnitude of cross-country wealth effects and distortions in allocations respectively. Further, we have shown that welfare reversals can arise even with an extended number of policy instruments under a variety of stabilization policies, including (Ramsey) optimal policies.

Finally, a robustness exercise has shown that our result is more fragile within a medium-scale model à la Smets and Wouters [2003]. Price indexation lowers the dispersion of producer prices and the welfare costs from nominal rigidities both under complete and incomplete markets, which favors complete market equilibria in terms of welfare. Wage rigidity also lowers the probability of welfare reversals, reducing the impact of cross-country wealth effects, on which welfare reversals crucially depend. In addition, we have shown that the shock structure chosen to represent the business cycle matters, as various combinations of driving forces can lead to different welfare rankings.

Overall, the paper presents a variety of situations where welfare reversals can occur within a monetary union. Given the high level of uncertainty concerning the "true" model of the European economy, it makes an important warning against the simplistic logic according to which further financial market integration within a monetary union always yields welfare gains. Further, given the documented inability of New-Keynesian models to price assets and risks correctly, our estimates may constitute a lower bound of the welfare losses from further financial market integration. A policy aimed at increasing real, trade and financial integration all together would undoubtedly minimize the chances of generating welfare costs, in comparison to financial market integration policies alone. Any policy seeking to make a monetary union behave as a homogeneous economy would attenuate reliance on financial markets to share risks, and hence, make welfare reversals irrelevant from the perspective of citizens. 


\section{References}

Backus, D. K., P. J. Kehoe, and F. E. Kydland, International Real Business Cycles: Theory vs. Evidence, Federal Reserve Bank of Minneapolis Quarterly Review, 1993, 17, 14-29.

Baxter, M. and M. J. Crucini, Business Cycles and the Asset Structure of Foreign Trade, International Economic Review, 1995, 36 (4), 821-54.

Beetsma, R. M. W. J. and H. Jensen, Monetary and Fiscal Policy Interactions in a Microfounded Model of Monetary Union, Journal of International Economics, 2005, 67 (2), 320352.

Benigno, P., Optimal Monetary Policy in a Currency Area, Journal of International Economics, 2004, 63 (2), 293-320.

, Price Stability with Imperfect Financial Integration, Journal of Money, Credit and Banking, 2009, 41 (1), 121-149.

and M. Woodford, Linear-quadratic Approximation of Optimal Policy Problems, Journal of Economic Theory, 2012, 147 (1), 1-42.

Broda, C. and D. W. Weinstein, Globalization and the Gains from Variety, Quarterly Journal of Economics, 2006, 21 (2), 541-585.

Calvo, G., Staggered Prices in a Utility-maximizing Framework, Journal of Monetary Economics, 1983, 12 (3), 383-398.

Candelon, B., J. Muysken, and R. Vermeulen, Fiscal Policy and Monetary Integration in Europe: An Update, Oxford Economic Papers, 2010, 62 (2), 323-349.

Chari, V. V., P. J Kehoe, and E. R. McGrattan, Can Sticky Price Models Generate Volatile and Persistent Real Exchange Rates?, Review of Economic Studies, 2002, 69 (3), 533-63.

de Paoli, B., Monetary Policy and Welfare in a Small Open Economy, Journal of International Economics, 2009, 77 (1), 11-22.

de Walque, G., F. Smets, and R. Wouters, An Estimated Two-Country DSGE Model for the Euro Area and the US Economy, Technical Report 2005. Available at: http://www.bankofcanada.ca/wp-content/uploads/2010/08/walque.pdf.

Farhi, E. and I. Werning, Fiscal Unions, 2013. Harvard and MIT mimeo, available at http://scholar.harvard.edu/files/farhi/files/fiscal-unions_update_july_2013.pdf.

Fatás, A. and I. Mihov, The Case For Restricting Fiscal Policy Discretion, The Quarterly Journal of Economics, 2003, 118 (4), 1419-1447.

Ferrero, A., Fiscal and Monetary Rules for a Currency Union, Journal of International Economics, 2009, 77 (1), 1-10.

Galí, J., The Return of The Wage Phillips Curve, Journal of the European Economic Association, 2011, 9 (3), 436-461. 
and R. Perotti, Fiscal Policy and Monetary Integration in Europe, Economic Policy, 2003, $18(37), 533-572$.

and T. Monacelli, Monetary Policy and Exchange Rate Volatility in a Small Open Economy, Review of Economic Studies, 2005, 72 (3), 707-734.

and ___ Optimal Monetary and Fiscal Policy in a Currency Union, Journal of International Economics, 2008, 76 (1), 116-132.

Giannoni, M. P. and M. Woodford, Optimal Interest-rate Rules: I. General Theory, NBER Working Paper No 9419, 2002.

Greenwood, J., Z. Hercowitz, and G. W. Huffman, Investment, Capacity Utilization, and the Real Business Cycle, American Economic Review, 1988, 78 (3), 402-17.

Harrigan, J., OECD Imports and Trade Barriers in 1983, Journal of International Economics, 1993, 35 (1-2), 91-111.

Hjorts $\varnothing$, I., Fiscal Policy Interactions and Imbalances in a Monetary Union, 2013. EUI mimeo, available at https://sites.google.com/site/idahjortso/research.

Ingram, J., Comment : The Optimum Currency Problem, in R. A. Mundell and A. Swoboda, editors, Monetary Problems in International Economy, Chicago University Press, 1969.

Kim, J. and S. H. Kim, Spurious Welfare Reversals in International Business Cycle Models, Journal of International Economics, 2003, 60 (2), 471-500.

Kirsanova, T. and S. Wren-Lewis, Optimal Fiscal Feedback on Debt in an Economy with Nominal Rigidities, The Economic Journal, 2012, 122 (559), 238-264.

, M. Satchi, D. Vines, and S. Wren-Lewis, Optimal Fiscal Policy Rules in a Monetary Union, Journal of Money, Credit and Banking, 2007, 39 (7), 1759-1784.

Levin, A. T., A. Onatski, J. Williams, and N. M. Williams, Monetary Policy Under Uncertainty in Micro-Founded Macroeconometric Models, in M. Gertler and K. Rogoff, editors, NBER Macroeconomics Annual 2005, National Bureau of Economic Research, Inc, 2006, pp. 229312.

López-Salido, D. and A. T. Levin, Optimal Monetary Policy with Endogenous Capital Accumulation, 2004 Meeting Papers 826, Society for Economic Dynamics 2004.

Lubik, T. and F. Schorfheide, A Bayesian Look at the New Open Economy Macroeconomics, in NBER Macroeconomics Annual 2005, Volume 20, National Bureau of Economic Research, Inc, 2006, pp. 313-382.

Lucas, R. J., Macroeconomic Priorities, American Economic Review, 2003, 93 (1), 1-14.

Mundell, R. A., Uncommon Arguments for Common Currencies, in H. G. Johnson and A. K. Swoboda, editors, The Economics of Common Currencies, Allen and Unwin, 1973, pp. 11432 . 
Pappa, E. and V. Vassilatos, The Unbearable Tightness of Being in a Monetary Union: Fiscal Restrictions and Regional Stability, European Economic Review, 2007, 51 (6), 1492-1513.

Pytlarczyk, E., An Estimated DSGE Model for the German Economy within the Euro Area, Discussion Paper Series 1: Economic Studies 33, Deutsche Bundesbank 2005.

Rumler, F., Estimates of the Open-Economy New Keynesian Phillips Curve for Euro Area Countries, Open Economies Review, 2007, 18 (4), 427-451.

Schmitt-Grohé, S. and M. Uribe, Closing Small Open Economy Models, Journal of International Economics, 2003, 61 (1), 163-185.

Senay, O. and A. Sutherland, Optimal Monetary Policy and the Timing of Asset Trade in Open Economies, Economics Letters, 2007, 95 (2), 297-302.

and __ , The Timing of Asset Trade and Optimal Policy in Dynamic Open Economies, Macroeconomic Dynamics, 2014, 17 (8).

Smets, F. and R. Wouters, An Estimated Dynamic Stochastic General Equilibrium Model of the Euro Area, Journal of the European Economic Association, 2003, 1 (5), 1123-1175.

Woodford, M., Commentary: How Should Monetary Policy Be Conducted in an Era of Price Stability?, in New Challenges for Monetary Policy, Kansas City: Federal Reserve Bank of Kansas City, 1999.

, Interest and Price, Princeton University Press, 2003.

Wyplosz, C., Fiscal Discipline in the EMU: Rules or Institutions?, Geneva Graduate Institute for International Studies, 2002. 


\section{A The stylized model}

\section{A.1 Assumptions}

The monetary union is composed of two areas of identical size, the home country and the foreign country. The representative household of the domestic economy maximizes a welfare index

$$
E_{t}\left\{\sum_{s=t}^{\infty} \beta^{s-t}\left(\log c_{s}-\chi \frac{n_{s}^{1+\psi}}{1+\psi}\right)\right\}, 0<\beta<1, \chi>0, \psi>0
$$

subject to the following budget constraint

$$
r_{t, t+1} b_{t}+p_{t} c_{t}=b_{t-1}+w_{t} n_{t}+\varphi_{t}-\operatorname{tax}_{t}
$$

In Equation (A.1), $\beta$ is the subjective discount factor, $c_{t}$ is the level of consumption and $n_{t}$ is the level of hours worked. In Equation (A.2), $b_{t}$ is the holding of a portfolio of Arrow-Debreu securities that are traded before policy choices are made (see Senay and Sutherland $(2007,2011)$ ). The portfolio delivers a state-contingent return $r_{t, t+1}$ between period $t$ and $t+1$. Risk-sharing is thus perfect. The CPI is denoted $p_{t}$, the nominal wage is $w_{t}, \varphi_{t}=\int_{0}^{1} \varphi_{t}(\omega) d \omega$ is the profit paid by the monopolistic firms to the domestic households, and $\operatorname{tax}_{t}$ is a lump-sum tax. Under complete markets, since foreign households solve a similar problem, first-order conditions are

$$
\begin{aligned}
\chi n_{t}^{\psi} c_{t} & =\frac{w_{t}}{p_{t}} \\
\chi n_{t}^{* \psi} c_{t}^{*} & =\frac{w_{t}^{*}}{p_{t}^{*}} \\
\beta E_{t}\left(\frac{r_{t} p_{t} c_{t}}{p_{t+1} c_{t+1}}\right) & =1 \\
\frac{p_{t}^{*} c_{t}^{*}}{p_{t} c_{t}} & =\Theta
\end{aligned}
$$

where stars characterize foreign variables. In these expressions, $r_{t}$ is the risk-free return on a one-period asset and $\Theta$ is a constant reflecting the initial foreign asset positions. From now on, we assume $\Theta=1$.

As an alternative financial market structure, we consider an extreme version of financial markets incompleteness and assume financial autarky. In this case, relative prices adjust to induce a zero trade balance each period. The risk-sharing condition (A.6) is therefore replaced by

$$
\frac{p_{t} c_{t}}{p_{h, t} y_{t}}=\frac{p_{t}^{*} c_{t}^{*}}{p_{f, t} y_{t}^{*}}=1
$$

while other first-order conditions remain unchanged.

Households also optimize over the composition of the consumption bundle (see Galí and Monacelli [2005] or Pappa and Vassilatos [2007]). Households consume both domestic and foreign goods. Both goods are imperfectly substitutable with elasticity of substitution $\mu>0$. In addition, households' preferences are biased towards local goods. We denote $(1-\alpha) \in[1 / 2,1]$ as the 
share of domestic goods in the consumption bundle of the domestic household and consider a symmetric structure for the consumption basket of the foreign household:

$$
c_{t}=\left((1-\alpha)^{\frac{1}{\mu}}\left(c_{h, t}\right)^{\frac{\mu-1}{\mu}}+\alpha^{\frac{1}{\mu}}\left(c_{f, t}\right)^{\frac{\mu-1}{\mu}}\right)^{\frac{\mu}{\mu-1}}, \text { and } c_{t}^{*}=\left((1-\alpha)^{\frac{1}{\mu}}\left(c_{h, t}^{*}\right)^{\frac{\mu-1}{\mu}}+\alpha^{\frac{1}{\mu}}\left(c_{f, t}^{*}\right)^{\frac{\mu-1}{\mu}}\right)^{\frac{\mu}{\mu-1}}
$$

Companion consumption price indices are

$$
p_{t}=\left((1-\alpha) p_{h, t}^{1-\mu}+\alpha p_{f, t}^{1-\mu}\right)^{\frac{1}{1-\mu}}, \text { and } p_{t}^{*}=\left((1-\alpha) p_{f, t}^{1-\mu}+\alpha p_{h, t}^{1-\mu}\right)^{\frac{1}{1-\mu}}
$$

where $p_{f, t}$ and $p_{h, t}$ denote the prices of goods produced in the home and foreign country respectively. The optimal allocation of expenditure between each type of good is thus given by

$$
\begin{aligned}
& c_{h, t}=(1-\alpha)\left(\frac{p_{h, t}}{p_{t}}\right)^{-\mu} c_{t} \text { and } c_{f, t}=\alpha\left(\frac{p_{f, t}}{p_{t}}\right)^{-\mu} c_{t} \\
& c_{f, t}^{*}=(1-\alpha)\left(\frac{p_{f, t}}{p_{t}^{*}}\right)^{-\mu} c_{t}^{*} \text { and } c_{h, t}^{*}=\alpha\left(\frac{p_{h, t}}{p_{t}^{*}}\right)^{-\mu} c_{t}^{*}
\end{aligned}
$$

Defining the terms of trade $s_{t}=p_{f, t} / p_{h, t}$, and using the structure of price indices, labor supply conditions are

$$
\begin{aligned}
\chi n_{t}^{\psi} c_{t} & =\frac{w_{t}}{p_{h, t}}\left(1-\alpha+\alpha s_{t}^{1-\mu}\right)^{\frac{1}{\mu-1}} \\
\chi n_{t}^{* \psi} c_{t}^{*} & =\frac{w_{t}^{*}}{p_{f, t}}\left(1-\alpha+\alpha s_{t}^{\mu-1}\right)^{\frac{1}{\mu-1}}
\end{aligned}
$$

Each type of good is a composite of national varieties with a constant elasticity of substitution $\theta>1$. Optimal variety demands are thus

$$
c_{i, t}(\omega)=\left(\frac{p_{i, t}(\omega)}{p_{i, t}}\right)^{-\theta} c_{i, t}, \text { and } c_{i, t}^{*}(\omega)=\left(\frac{p_{i, t}(\omega)}{p_{i, t}}\right)^{-\theta} c_{i, t}^{*}, \text { for } i=h, f
$$

In each country, a unit continuum of firms indexed in $\omega$ produce varieties of each type of good according to

$$
y_{t}(\omega)=a_{t} n_{t}(\omega) \text { and } y_{t}^{*}(\omega)=a_{t}^{*} n_{t}^{*}(\omega)
$$

where $a_{t}$ and $a_{t}^{*}$ are exogenous measures of productivity. Following Calvo [1983], prices are set optimally subject to the constraint that only a fraction $(1-\eta) \in[0,1]$ of producers is allowed to reset prices, other producers updating prices at the pace of steady-state inflation $\pi_{h}=\pi_{f}=1$, and subject to the variety demands of households. The corresponding optimal pricing condition for re-setters is

$$
\mathrm{p}_{h, t}(\omega)=\frac{\theta}{(\theta-1)(1-\tau)} \frac{E_{t} \sum_{s=0}^{\infty}\left(\beta \eta^{h}\right) w_{t+s} y_{t+s}(\omega)\left(p_{h, t+s} a_{t+s} c_{t+s}\right)^{-1}}{E_{t} \sum_{s=0}^{\infty}\left(\beta \eta^{h}\right) y_{t+s}(\omega) c_{t+s}^{-1}}
$$

where $\tau$ is a constant tax introduced to offset the first-order distortions related to monopolistic competition. The optimal steady-state level of this tax is negative, and so turns out to be a subsidy, financed by the lump-sum tax imposed on the household. Government budget constraints are thus

$$
\operatorname{tax}_{t}+\tau \int_{0}^{1} p_{h, t}(\omega) y_{t}(\omega)=0, \text { and } \operatorname{tax}_{t}^{*}+\tau \int_{0}^{1} p_{f, t}(\omega) y_{t}^{*}(\omega)=0
$$


The aggregation of the model is straightforward as goods market clearing condition are

$$
y_{t}=(1-\alpha)\left(\frac{p_{h, t}}{p_{t}}\right)^{-\mu} c_{t}+\alpha\left(\frac{p_{h, t}}{p_{t}^{*}}\right)^{-\mu} c_{t}^{*}, \text { and } y_{t}^{*}=(1-\alpha)\left(\frac{p_{f, t}}{p_{t}^{*}}\right)^{-\mu} c_{t}^{*}+\alpha\left(\frac{p_{f, t}}{p_{t}}\right)^{-\mu} c_{t}
$$

while labor market clearing conditions are

$$
n_{t}=\int_{0}^{1} n_{t}(\omega) d \omega, \text { and } n_{t}^{*}=\int_{0}^{1} n_{t}^{*}(\omega) d \omega
$$

implying that aggregate production functions are

$$
y_{t} \Upsilon_{t}=a_{t} n_{t}, \text { and } y_{t}^{*} \Upsilon_{t}^{*}=a_{t}^{*} n_{t}^{*}
$$

where $\Upsilon_{t}$ and $\Upsilon_{t}^{*}$ denote the dispersion of producer prices.

\section{A.2 Steady state and linearization}

Assuming $a=a^{*}=1, \chi=1$ and $\tau=(1-\theta)^{-1}$, the symmetric steady state of this economy is $r=1 / \beta, y=y^{*}=c=c^{*}=\pi_{h}=\pi_{f}=\pi=\pi^{*}=1, p_{h}=p_{f}=p=p^{*}=w=w^{*}$. As in any cashless economy, nominal price levels are undetermined. We thus assume $p=1$ without loss of generality. Linearizing the labor supply equations, combining with production functions and assuming symmetric nominal rigidities, the dynamics of inflation rates are

$$
\begin{aligned}
& \widehat{\pi}_{h, t}=\beta E_{t} \widehat{\pi}_{h, t+1}+\kappa\left(\psi \widehat{y}_{t}+\widehat{c}_{t}+\alpha \widehat{s}_{t}-(1+\psi) \widehat{a}_{t}\right) \\
& \widehat{\pi}_{f, t}=\beta E_{t} \widehat{\pi}_{f, t+1}+\kappa\left(\psi \widehat{y}_{t}^{*}+\widehat{c}_{t}^{*}-\alpha \widehat{s}_{t}-(1+\psi) \widehat{a}_{t}^{*}\right)
\end{aligned}
$$

where hats denote logs and $\kappa=(1-\eta)(1-\beta \eta) / \eta$. Under complete markets, the risk-sharing condition yields

$$
\widehat{c}_{t}=\widehat{c}_{t}^{*}+(1-2 \alpha) \widehat{s}_{t}
$$

while under autarky we have

$$
\widehat{c}_{t}=\widehat{c}_{t}^{*}+\widehat{y}_{t}-\widehat{y}_{t}^{*}-2 \alpha \widehat{s}_{t}
$$

Goods market clearing conditions are

$$
\begin{aligned}
\widehat{y}_{t} & =(1-\alpha) \widehat{c}_{t}+\alpha \widehat{c}_{t}^{*}+2 \mu \alpha(1-\alpha) \widehat{s}_{t} \\
\widehat{y}_{t}^{*} & =(1-\alpha) \widehat{c}_{t}^{*}+\alpha \widehat{c}_{t}-2 \mu \alpha(1-\alpha) \widehat{s}_{t}
\end{aligned}
$$

The model is closed by considering the dynamics of consumption. We assume that the central bank of the monetary union fully stabilizes the union-wide inflation rate at all times, so that

$$
\widehat{\pi}_{h, t}+\widehat{\pi}_{f, t}=\widehat{\pi}_{t}+\widehat{\pi}_{t}^{*}=0
$$

As a consequence, union-wide consumption and output are just

$$
\widehat{y}_{t}+\widehat{y}_{t}^{*}=\widehat{c}_{t}+\widehat{c}_{t}^{*}=\widehat{a}_{t}+\widehat{a}_{t}^{*}
$$

While union-wide variables are determined independently of the structure of financial markets, relative variables are not. Defining $\widehat{x}_{t}^{r}=\widehat{x}_{t}^{*}-\widehat{x}_{t}, \forall x$, using the definition of terms of trade, and combining both Phillips curves, terms of trade evolve according to

$$
\widehat{\pi}_{t}^{r}=\beta E_{t} \widehat{\pi}_{t+1}^{r}+\kappa\left(\psi \widehat{y}_{t}^{r}+\widehat{c}_{t}^{r}-2 \alpha \widehat{s}_{t}-(1+\psi) \widehat{a}_{t}^{r}\right)
$$


The goods market clearing condition is

$$
\widehat{y}_{t}^{r}=(1-2 \alpha) \widehat{c}_{t}^{r}-4 \mu \alpha(1-\alpha) \widehat{s}_{t}
$$

and the international condition is given by

$$
\left\{\begin{array}{cc}
\widehat{c}_{t}^{r}=(2 \alpha-1) \widehat{s}_{t} & \text { under complete markets } \\
\widehat{c}_{t}^{r}=\widehat{y}_{t}^{r}+2 \alpha \widehat{s}_{t} & \text { under financial autarky }
\end{array}\right.
$$

\section{A.3 Welfare}

We start from the following second-order approximation of the utility function and using $n=$ $\chi=1$, we get

$$
u_{t} \simeq u+\widehat{c}_{t}-\widehat{n}_{t}-\frac{(1+\psi)}{2} \widehat{n}_{t}^{2}
$$

An exact log-transformation of the aggregate production function gives

$$
\widehat{n}_{t}=\widehat{y}_{t}+\widehat{\Upsilon}_{t}-\widehat{a}_{t}
$$

so that

$$
u_{t} \simeq \widehat{c}_{t}-\widehat{y}_{t}-\widehat{\Upsilon}_{t}-\frac{(1+\psi)}{2}\left(\widehat{y}_{t}^{2}-2 \widehat{y}_{t} \widehat{a}_{t}\right)+O\left(\|\xi\|^{3}\right)
$$

where $O\left(\|\xi\|^{3}\right)$ captures terms of order 3 and higher. Exogenous terms like shocks are also omitted. As shown by Galí and Monacelli [2005], $\widehat{\Upsilon}_{t}$ is of second-order so $\widehat{\Upsilon}_{t} \widehat{y}_{t}$ or $\widehat{\Upsilon}_{t} \widehat{a}_{t}$ and $\widehat{\Upsilon}_{t}^{2}$ are of third and fourth order respectively, and included in $O\left(\|\xi\|^{3}\right)$. Deriving a similar second-order approximation of the utility function for foreign households and considering union-wide welfare gives

$$
u_{t}+u_{t}^{*} \simeq \widehat{c}_{t}+\widehat{c}_{t}^{*}-\left(\widehat{y}_{t}+\widehat{y}_{t}^{*}\right)-\left(\widehat{\Upsilon}_{t}+\widehat{\Upsilon}_{t}^{*}\right)-\frac{(1+\psi)}{2}\left(\left(\widehat{y}_{t}^{2}-2 \widehat{y}_{t} \widehat{a}_{t}\right)+\left(\widehat{y}_{t}^{* 2}-2 \widehat{y}_{t}^{*} \widehat{a}_{t}^{*}\right)\right)+O\left(\|\xi\|^{3}\right)
$$

A second-order approximation of goods market clearing conditions is then used

$$
\widehat{y}_{t}+\widehat{y}_{t}^{*}=\widehat{c}_{t}+\widehat{c}_{t}^{*}+\frac{1}{2} \widehat{c}_{t}^{2}+\frac{1}{2} \widehat{c}_{t}^{* 2}+\mu \alpha(1-\alpha) \widehat{s}_{t}^{2}-\frac{1}{2} \widehat{y}_{t}^{2}-\frac{1}{2} \widehat{y}_{t}^{* 2}+O\left(\|\xi\|^{3}\right)
$$

and plugged in the previous equation

$$
u_{t}+u_{t}^{*} \simeq-\frac{1}{2} \widehat{c}_{t}^{2}-\frac{1}{2} \widehat{c}_{t}^{* 2}-\mu \alpha(1-\alpha) \widehat{s}_{t}^{2}-\frac{\psi}{2}\left(\widehat{y}_{t}^{2}+\widehat{y}_{t}^{* 2}\right)-\left(\widehat{\Upsilon}_{t}+\widehat{\Upsilon}_{t}^{*}\right)+(1+\psi)\left(\widehat{y}_{t} \widehat{a}_{t}+\widehat{y}_{t}^{*} \widehat{a}_{t}^{*}\right)+O\left(\|\xi\|^{3}\right)
$$

We now use

$$
\begin{aligned}
\widehat{y}_{t}^{2}+\widehat{y}_{t}^{* 2} & =\frac{1}{2}\left(\widehat{y}_{t}^{2}+\widehat{y}_{t}^{* 2}\right)^{2}+\frac{1}{2}\left(\widehat{y}_{t}^{* 2}-\widehat{y}_{t}^{2}\right)^{2}=\frac{1}{2}\left(\widehat{y}_{t}^{u}\right)^{2}+\frac{1}{2}\left(\widehat{y}_{t}^{r}\right)^{2}+O\left(\|\xi\|^{3}\right) \\
\widehat{c}_{t}^{2}+\widehat{c}_{t}^{* 2} & =\frac{1}{2}\left(\widehat{c}_{t}^{2}+\widehat{c}_{t}^{* 2}\right)^{2}+\frac{1}{2}\left(\widehat{c}_{t}^{* 2}-\widehat{c}_{t}^{2}\right)^{2}=\frac{1}{2}\left(\widehat{c}_{t}^{u}\right)^{2}+\frac{1}{2}\left(\widehat{c}_{t}^{r}\right)^{2}+O\left(\|\xi\|^{3}\right)
\end{aligned}
$$

Because of our assumption about monetary policy, the following relation holds

$$
\widehat{y}_{t}+\widehat{y}_{t}^{*}=\widehat{c}_{t}+\widehat{c}_{t}^{*}=\widehat{a}_{t}+\widehat{a}_{t}^{*}
$$


The welfare function thus simplifies to

$$
u_{t}+u_{t}^{*} \simeq-\frac{1}{4}\left(\widehat{c}_{t}^{r}\right)^{2}-\mu \alpha(1-\alpha) \widehat{s}_{t}^{2}-\frac{\psi}{4}\left(\widehat{y}_{t}^{r}\right)^{2}-\left(\widehat{\Upsilon}_{t}+\widehat{\Upsilon}_{t}^{*}\right)+(1+\psi)\left(\widehat{y}_{t} \widehat{a}_{t}+\widehat{y}_{t}^{*} \widehat{a}_{t}^{*}\right)+O\left(\|\xi\|^{3}\right)
$$

In addition,

$$
\widehat{y}_{t} \widehat{a}_{t}+\widehat{y}_{t}^{*} \widehat{a}_{t}^{*}=\frac{1}{2} \underbrace{\left(\widehat{y}_{t}+\widehat{y}_{t}^{*}\right)}_{\widehat{y}_{t}^{u}} \underbrace{\left(\widehat{a}_{t}+\widehat{a}_{t}^{*}\right)}_{\widehat{a}_{t}^{u}}+\frac{1}{2}(\underbrace{\left(\widehat{y}_{t}^{*}-\widehat{y}_{t}\right.}_{\widehat{y}_{t}^{*}}) \underbrace{\left(\widehat{a}_{t}^{*}-\widehat{a}_{t}\right)}_{\widehat{a}_{t}^{*}}
$$

which, using $\widehat{y}_{t}^{u}=\widehat{a}_{t}^{u}$ yields ${ }^{19}$

$$
u_{t}+u_{t}^{*} \simeq-\frac{1}{4}\left(\widehat{c}_{t}^{r}\right)^{2}-\mu \alpha(1-\alpha) \widehat{s}_{t}^{2}-\frac{\psi}{4}\left(\widehat{y}_{t}^{r}\right)^{2}-\left(\widehat{\Upsilon}_{t}+\widehat{\Upsilon}_{t}^{*}\right)+\frac{(1+\psi)}{2} \widehat{y}_{t}^{r} \widehat{a}_{t}^{r}+O\left(\|\xi\|^{3}\right)
$$

Let us define

$$
\begin{aligned}
\widetilde{c}_{t}^{r} & =\frac{(1-2 \alpha)(1+\psi)}{1+\lambda^{c} \psi} \widehat{a}_{t}^{r} \\
\widetilde{y}_{t}^{r} & =\frac{\lambda^{c}(1+\psi)}{1+\lambda^{c} \psi} \widehat{a}_{t}^{r} \\
\widetilde{s}_{t} & =-\frac{1+\psi}{1+\lambda^{c} \psi} \widehat{a}_{t}^{r}
\end{aligned}
$$

with $\lambda^{c}=1+4(\mu-1) \alpha(1-\alpha) \geq 0$, where tildes denote the equilibrium under flexible prices and complete markets. Using these equations:

$$
\begin{aligned}
\frac{(1+\psi)}{2} \widehat{y}_{t}^{r} \widehat{a}_{t}^{r} & =\underbrace{\frac{\psi}{2} \frac{\lambda^{c}(1+\psi)}{1+\lambda^{c} \psi} \widehat{a}_{t}^{r} \widehat{y}_{t}^{r}+\frac{(1+\psi)}{2\left(1+\lambda^{c} \psi\right)} \widehat{y}_{t}^{r} \widehat{a}_{t}^{r}}_{\frac{\psi}{2} \widehat{y}_{t}^{r}} \\
& =\frac{\psi}{2} \widehat{y}_{t}^{r} \widehat{y}_{t}^{r}+\underbrace{\frac{(1+\psi)(1-2 \alpha)}{2\left(1+\lambda^{c} \psi\right)} \widehat{a}_{t}^{r} \widehat{c}_{t}^{r}}_{\frac{1}{2} \widetilde{c}_{t}^{r}}-\underbrace{\frac{4 \mu \alpha(1-\alpha)(1+\psi)}{2(1+\lambda c \psi} \widehat{a}_{t}^{r}}_{-2 \mu \alpha(1-\alpha) \widetilde{s}_{t}} \widehat{s}_{t} \\
& =\frac{\psi}{2} \widehat{y}_{t}^{r} \widehat{y}_{t}^{r}+\frac{1}{2} \widetilde{c}_{t}^{r} \widehat{c}_{t}^{r}+2 \mu \alpha(1-\alpha) \widetilde{s}_{t} \widehat{s}_{t}
\end{aligned}
$$

Plugging in the welfare function

$$
u_{t}+u_{t}^{*} \simeq-\frac{1}{4}\left(\widehat{c}_{t}^{r}-\widetilde{c}_{t}^{r}\right)^{2}-\mu \alpha(1-\alpha)\left(\widehat{s}_{t}-\widetilde{s}_{t}\right)^{2}-\frac{\psi}{4}\left(\widehat{y}_{t}^{r}-\widetilde{y}_{t}^{r}\right)^{2}-\left(\widehat{\Upsilon}_{t}+\widehat{\Upsilon}_{t}^{*}\right)+O\left(\|\xi\|^{3}\right)
$$

Now the lifetime welfare measure, using the result of Woodford [2003] can be expressed as

$W_{t} \simeq E_{t}\left\{\sum_{s=t}^{\infty} \beta^{s-t}\left(-\frac{1}{4}\left(\widehat{c}_{s}^{r}-\widetilde{c}_{s}^{r}\right)^{2}-\mu \alpha(1-\alpha)\left(\widehat{s}_{s}-\widetilde{s}_{s}\right)^{2}-\frac{\psi}{4}\left(\widehat{y}_{s}^{r}-\widetilde{y}_{s}^{r}\right)^{2}-\frac{\theta \widehat{\pi}_{h, s}^{2}}{2 \kappa^{h}}-\frac{\theta \widehat{\pi}_{f, s}^{2}}{2 \kappa^{f}}\right)\right\}+O\left(\|\xi\|^{3}\right)$

Recalling that we consider symmetric nominal rigidities $\kappa^{h}=\kappa^{f}=\kappa$ and using

$$
\begin{aligned}
& \widehat{\pi}_{h, t}=\frac{1}{2} \underbrace{\left(\widehat{\pi}_{h, t}+\widehat{\pi}_{f, t}\right)}_{=0}-\frac{1}{2} \widehat{\pi}_{t}^{r} \\
& \widehat{\pi}_{f, t}=\frac{1}{2} \underbrace{\left(\widehat{\pi}_{h, t}+\widehat{\pi}_{f, t}\right)}_{=0}+\frac{1}{2} \widehat{\pi}_{t}^{r}
\end{aligned}
$$

\footnotetext{
${ }^{19}$ Terms that depend on exogenous shocks only are irrelevant to compare welfare under alternative financial market structures, that affect the path of endogenous variables.
} 
we get

$$
W_{t} \simeq-\frac{1}{4} E_{t}\left\{\sum_{s=t}^{\infty} \beta^{s-t}\left(\left(\widehat{c}_{s}^{r}-\widetilde{c}_{s}^{r}\right)^{2}+4 \mu \alpha(1-\alpha)\left(\widehat{s}_{s}-\widetilde{s}_{s}\right)^{2}+\psi\left(\widehat{y}_{s}^{r}-\widetilde{y}_{s}^{r}\right)^{2}+\theta \kappa^{-1}\left(\widehat{\pi}_{s}^{r}\right)^{2}\right)\right\}+O\left(\|\xi\|^{3}\right)
$$

\section{A.4 Equilibria under flexible prices}

We compare variances under alternative financial markets structures:

$$
\begin{aligned}
\operatorname{var}\left(\widetilde{s}_{t}\right)-\operatorname{var}\left(\widehat{s}_{t}\right) & =\left(\left(\digamma_{s}^{c}\right)^{2}-\left(\digamma_{s}^{a}\right)^{2}\right) \operatorname{var}\left(\widehat{a}_{t}^{r}\right) \\
\operatorname{var}\left(\widehat{c}_{t}^{r}\right)-\operatorname{var}\left(\widehat{c}_{t}^{r}\right) & =\left(\left(\digamma_{c}^{c}\right)^{2}-\left(\digamma_{c}^{a}\right)^{2}\right) \operatorname{var}\left(\widehat{a}_{t}^{r}\right) \\
\operatorname{var}\left(\widehat{y}_{t}^{r}\right)-\operatorname{var}\left(\widehat{y}_{t}^{r}\right) & =\left(\left(\digamma_{y}^{c}\right)^{2}-\left(\digamma_{y}^{a}\right)^{2}\right) \operatorname{var}\left(\widehat{a}_{t}^{r}\right)
\end{aligned}
$$

Given the domains of parameters considered, we have $\psi \geq 0, \lambda^{c}>0$, and $\lambda^{a}>0$. Therefore

$$
\operatorname{sign}\left(\operatorname{var}\left(\widetilde{s}_{t}\right)-\operatorname{var}\left(\widehat{s}_{t}\right)\right)=\operatorname{sign}\left[(1+\psi) \lambda^{a}-\left(1+\lambda^{c} \psi\right)\right]
$$

which using the definitions of $\lambda^{c}=1+4(\mu-1) \alpha(1-\alpha)$, and $\lambda^{a}=1+2(\mu-1)(1-\alpha)$, can be written as

$$
\operatorname{sign}\left[(1+\psi)\left(\lambda^{a}\right)-\left(1+\lambda^{c} \psi\right)\right]=\operatorname{sign}[2(\mu-1)(1-\alpha)(1+\psi(1-2 \alpha))]
$$

Therefore, given the domains of parameters,

$$
\operatorname{sign}\left(\operatorname{var}\left(\widetilde{s}_{t}\right)-\operatorname{var}\left(\widehat{s}_{t}\right)\right)=\operatorname{sign}(\mu-1)
$$

When $\mu>1$, under flexible prices terms of trade are more volatile under complete markets. Using a similar approach,

$$
\begin{aligned}
\operatorname{sign}\left(\operatorname{var}\left(\widehat{c}_{t}^{r}\right)-\operatorname{var}\left(\widehat{c}_{t}^{r}\right)\right) & =\operatorname{sign}\left[(1-2 \alpha)(1+\psi) \lambda^{a}-\left(\lambda^{a}-2 \alpha\right)\left(1+\lambda^{c} \psi\right)\right] \\
& =\operatorname{sign}\left[4 ( 1 - \mu ) \alpha ( 1 - \alpha ) \left(1+\psi+\psi(1-2 \alpha+2(\mu-1)(1-\alpha)){ }^{\prime}\right.\right.
\end{aligned}
$$

thus, when $\mu>1, \operatorname{var}\left(\widehat{c}_{t}^{r}\right)<\operatorname{var}\left(\widehat{c}_{t}^{r}\right)$, and relative consumptions are less volatile under complete markets under flexible prices. Lastly,

$$
\operatorname{sign}\left(\operatorname{var}\left(\widetilde{y}_{t}^{r}\right)-\operatorname{var}\left(\widehat{y}_{t}^{r}\right)\right)=\operatorname{sign}\left(\frac{\lambda^{c}-1}{1+\lambda^{c} \psi}\right)=\operatorname{sign}(\mu-1)
$$

so relative outputs are more volatile under complete markets under flexible prices when $\mu>1$.

\section{A.5 Equilibria under sticky prices}

\section{A.5.1 Complete markets}

Under complete markets, we get the following dynamics of terms of trade

$$
\Delta \widehat{s}_{t}=\beta E_{t} \Delta \widehat{s}_{t+1}+\kappa\left(-\left(1+\lambda^{c} \psi\right) \widehat{s}_{t}-(1+\psi) \widehat{a}_{t}^{r}\right)
$$


where $\lambda^{c}=(1-2 \alpha)^{2}+4 \mu \alpha(1-\alpha)$, and where relative products and consumptions are

$$
\begin{aligned}
\widehat{y}_{t}^{r} & =-\lambda^{c} \widehat{s}_{t} \\
\widehat{c}_{t}^{r} & =(2 \alpha-1) \widehat{s}_{t}
\end{aligned}
$$

Finally, using the expression of terms of trade under flexible prices and complete markets $\widetilde{s}_{t}=$ $-\frac{1+\psi}{1+\lambda^{c} \psi} \widehat{a}_{t}^{r}$, we get

$$
\Delta \widehat{s}_{t}=\beta E_{t} \Delta \widehat{s}_{t+1}-\varepsilon\left(\widehat{s}_{t}-\widetilde{s}_{t}\right)
$$

where $\varepsilon=\kappa\left(1+\lambda^{c} \psi\right)$. Because this equation has a forward and a backward component, the saddle path condition requires that the lag polynomial admits one root outside the unit circle and one root inside. Rewriting this equation using the lag $(L)$ and the lead $\left(L^{-1}\right)$ operator we get

$$
-E_{t}\left(L^{-1}\left(L^{2}-\delta_{\text {com }} L+\beta\right) \widehat{s}_{t}\right)=\varepsilon \widetilde{s}_{t}
$$

where $\delta_{\text {com }}=(1+\beta+\varepsilon)$. Let us focus on the determinant of the polynomial $\delta_{\text {com }}^{2}-4 \beta$. First, $\kappa \geq 0$ and $\lambda^{c}>0$ which means that $\varepsilon=\kappa\left(1+\lambda^{c} \psi\right) \geq 0$. If $\varepsilon$ is large, i.e. with low nominal rigidities, it is clear that $\delta_{\text {com }}^{2}-4 \beta>0$. Second,

$$
\lim _{\varepsilon \rightarrow 0} \delta_{c o m}^{2}-4 \beta=1+\beta^{2}-2 \beta=(1-\beta)^{2}>0
$$

Therefore the polynomial always admits two roots:

$$
\lambda_{1}=\frac{\delta_{c o m}-\sqrt{\delta_{c o m}^{2}-4 \beta}}{2}, \text { and } \lambda_{2}=\frac{\delta_{c o m}+\sqrt{\delta_{c o m}^{2}-4 \beta}}{2}
$$

We can further check that $0<\lambda_{1}<1$ and that $\lambda_{2}>1$. Remind that $\delta_{\text {com }}>0$ and that, since $\beta>0, \delta_{\text {com }}-\sqrt{\delta_{\text {com }}^{2}-4 \beta}<1$ always, which means $0<\lambda_{1}<1$. Finally, because

$$
\lim _{\varepsilon \rightarrow 0} \lambda_{2}=1, \text { and } \lim _{\varepsilon \rightarrow \infty} \lambda_{2}=\infty, \forall 0<\beta<1
$$

and because $\lambda_{2}$ is a continuous and strictly increasing function in both $\varepsilon$ and $\beta$ on their respective domains, $\lambda_{2}>1$ always. So the equation always delivers the following saddle path solution

$$
\left(1-\frac{L}{\lambda_{2}}\right) \widehat{s}_{t}=\frac{1}{\lambda_{2}} E_{t}\left(\frac{\varepsilon}{\left(1-\lambda_{1} L^{-1}\right)} \widetilde{s}_{t}\right)
$$

or

$$
\widehat{s}_{t}=\lambda_{2}^{-1}\left(\widehat{s}_{t-1}+\varepsilon \sum_{s=0}^{\infty} \lambda_{1}^{s} E_{t}\left(\widetilde{s}_{t+s}\right)\right)
$$

where, since $\lambda_{1}<1$, we have used the fact that $\frac{1}{1-\lambda_{1} L^{-1}}=\left(1+\lambda_{1} L^{-1}+\lambda_{1}^{2} L^{-2}+\ldots+\lambda_{1}^{\infty} L^{-\infty}\right)$. Finally, substituting the values of $\lambda_{2}$ and $\lambda_{1}$ :

$$
\widehat{s}_{t}=\rho_{1, \mathrm{com}} \widehat{s}_{t-1}+\varepsilon \rho_{1, \mathrm{com}} \sum_{s=0}^{\infty}\left(\rho_{2, \mathrm{com}}\right)^{s} E_{t}\left(\widetilde{s}_{t+s}\right)
$$

where $\rho_{1, \text { com }}=\left(\frac{1}{2}\left(\delta_{\text {com }}+\sqrt{\delta_{\text {com }}^{2}-4 \beta}\right)\right)^{-1}$ and $\rho_{2, \text { com }}=\frac{1}{2}\left(\delta_{\text {com }}-\sqrt{\delta_{c o m}^{2}-4 \beta}\right)$. As a function of structural shocks, we get

$$
\widehat{s}_{t}=\rho_{1, \mathrm{com}} \widehat{s}_{t-1}-\kappa \rho_{1, \mathrm{com}}(1+\psi) \sum_{s=0}^{\infty}\left(\rho_{2, \mathrm{com}}\right)^{s} E_{t}\left(\widehat{a}_{t+s}^{r}\right)
$$




\section{A.5.2 Autarky}

Under autarky, the dynamics of terms of trade is

$$
\Delta \widehat{s}_{t}=\beta E_{t} \Delta \widehat{s}_{t+1}+\kappa\left(-(1+\psi) \lambda^{a} \widehat{s}_{t}-(1+\psi) \widehat{a}_{t}^{r}\right)
$$

where $\lambda^{a}=1+2(\mu-1)(1-\alpha)$ and relative products and consumptions are

$$
\begin{aligned}
\widehat{y}_{t}^{r} & =-\lambda^{a} \widehat{s}_{t} \\
\widehat{c}_{t}^{r} & =(1-2 \mu(1-\alpha)) \widehat{s}_{t}
\end{aligned}
$$

Again, using the flexible prices expression of terms of trade, we get

$$
\Delta \widehat{s}_{t}=\beta E_{t} \Delta \widehat{s}_{t+1}-\varepsilon\left(\Phi \widehat{s}_{t}-\widetilde{s}_{t}\right)
$$

where $\Phi=\frac{(1+\psi) \lambda^{a}}{1+\lambda^{c} \psi}$. Just as in the previous case, we can derive the analytical solution to this equation

$$
-E_{t}\left(L^{-1}\left(L^{2}-\delta L+\beta\right) \widehat{s}_{t}\right)=\varepsilon \widetilde{s}_{t}
$$

where $\delta_{\text {aut }}=(1+\beta+\varepsilon \Phi)$. Let us focus on the determinant of the polynomial $\delta_{\text {aut }}^{2}-4 \beta$. Now because $\lambda^{a}$ can be negative, $\Phi$ can also be negative and the analysis of the complete market case would not carry over the case of financial autarky. The conditions to have $\lambda^{a}>0$ are rather loose, however, since $\lambda^{a}>0$ as long as

$$
\mu>\frac{1 / 2-\alpha}{1-\alpha},
$$

which means that $\mu$ has to be higher than $1 / 2$ for a closed economy and can be lower in the case of higher trade openness. From now on, we assume $\mu>1 / 2$, which means that the polynomial governing the dynamics of terms of trade under autarky always admits two roots, one outside and one inside the unit circle. Now the solution of the terms-of-trade equation is

$$
\widehat{s}_{t}=\rho_{1, a u t} \widehat{s}_{t-1}-\kappa \rho_{1, a u t}(1+\psi) \sum_{s=0}^{\infty}\left(\rho_{2, a u t}\right)^{s} E_{t}\left(\widehat{a}_{t+s}^{r}\right)
$$

where $\rho_{1, a u t}=\left(\frac{1}{2}\left(\delta_{\text {aut }}+\sqrt{\delta_{\text {aut }}^{2}-4 \beta}\right)\right)^{-1}$, and $\rho_{2, a u t}=\frac{1}{2}\left(\delta_{\text {aut }}-\sqrt{\delta_{\text {aut }}^{2}-4 \beta}\right)$.

\section{A.5.3 Variances}

Proposition 2 When $\mu>1, \delta_{\text {aut }}>\delta_{\text {com }}$ which implies $\rho_{1, \text { aut }}<\rho_{1, \text { com }}$ and $\rho_{2, \text { aut }}<\rho_{2, \text { com }}$.

Proof. In general, $\operatorname{sign}\left(\delta_{\text {aut }}-\delta_{\text {com }}\right)=\operatorname{sign}((2(1-\alpha)+2 \psi(1-\alpha)(1-2 \alpha))(\mu-1))$, which, because $0<\alpha<1 / 2$ implies $\operatorname{sign}\left(\delta_{\text {aut }}-\delta_{\text {com }}\right)=\operatorname{sign}(\mu-1)$.

Proposition 3 When $\mu>1$, terms of trade are more volatile under complete markets than under financial autarky, while they are less volatile when $\mu<1$.

Proof. Under rational expectations, $E_{t}\left(\widehat{a}_{t+s}^{r}\right)=\rho_{a} \widehat{a}_{t}^{r}$ where $\rho_{a}$ is the persistence of the productivity process, so that

$$
\widehat{s}_{t}=\rho_{1} \widehat{s}_{t-1}-\varphi \widehat{a}_{t}^{r}
$$


where $\varphi=\kappa \rho_{1}(1+\psi) /\left(1-\rho_{2} \rho_{a}\right)$, which implies

$$
\operatorname{var}\left(\widehat{s}_{t}\right)=\frac{\varphi^{2}}{1-\rho_{1}^{2}} \frac{1+\rho_{1} \rho_{a}}{1-\rho_{1} \rho_{a}} \operatorname{var}\left(\widehat{a}_{t}^{r}\right)
$$

This equation shows that $\rho_{1}$ and $\rho_{2}$ affect positively the variance of terms of trade. Using the result of Proposition 2 gives the result.

Proposition 4 The variance of relative inflation rates is also higher under complete markets than under autarky when $\mu>1$.

Proof. Using the solution of Equation (A.80) in difference also allows us to derive the analytical expression of $\operatorname{var}\left(\Delta \widehat{s}_{t}\right)$, that is of the variance of relative inflation rates

$$
\operatorname{var}\left(\Delta \widehat{s}_{t}\right)=\frac{\varphi^{2} 2\left(1-\rho_{a}\right)}{1-\rho_{1}^{2}}\left(\frac{1-\rho_{1}}{1-\rho_{1} \rho_{a}}\right) \operatorname{var}\left(\widehat{a}_{t}^{r}\right)
$$

While the effect of $\rho_{2}$ on the variance of $\Delta \widehat{s}_{t}$ is unambiguously positive, the effect of $\rho_{1}$ is less clear. However, it can be shown that

$$
\operatorname{sign}\left(\frac{\partial \operatorname{var}\left(\Delta \widehat{s}_{t}\right)}{\partial \rho_{1}}\right)=\operatorname{sign}\left(2\left(1-\rho_{1} \rho_{a}\right)-\rho_{1}\left(1+\rho_{1}\right)\left(1-\rho_{a}\right)\right)>0
$$

as $\rho_{1}\left(1+\rho_{1}\right)<2$ and $\left(1-\rho_{a}\right)<\left(1-\rho_{1} \rho_{a}\right)$ since $\rho_{1}<1$. As both $\rho_{1}$ and $\rho_{2}$ affect positively the volatility of relative inflation rates, the latter is higher under complete markets if $\mu>1$.

\section{A.6 Analytical expression of welfare}

We start with the difference between the variance of key welfare variables under complete markets and autarky:

$$
\begin{aligned}
& \operatorname{var}_{\text {aut }}\left(\widehat{c}_{t}^{r}-\widetilde{c}_{t}^{r}\right)-\operatorname{var}_{\text {com }}\left(\widehat{c}_{t}^{r}-\widetilde{c}_{t}^{r}\right)=\left(\begin{array}{c}
(1-2 \mu(1-\alpha))^{2} \frac{\varphi_{\text {aut }}^{2}}{1-\rho_{1, \text { aut }}^{2}} \frac{1+\rho_{1, a u t} \rho_{a}}{1-\rho_{1,1 a u t} \rho_{a}} \\
-(2 \alpha-1)^{2} \frac{\varphi_{\text {com }}^{2}}{1-\rho_{1, \text { com }}^{2}} \frac{1+\rho_{1, \text { com }} \rho_{a}}{1-\rho_{1, \text { com }} \rho_{a}}
\end{array}\right) \operatorname{var}\left(\widehat{a}_{t}^{r}\right) \\
& +2(1-2 \alpha) \frac{1+\psi}{1+\lambda^{c} \psi}\left(\begin{array}{c}
\frac{(1-2 \alpha) \varphi_{\text {com }}}{1-\rho_{1, c o m} \rho_{a}} \\
-\frac{(2 \mu(1-\alpha)-1) \varphi_{a u t}}{1-\rho_{1, a u t} \rho_{a}}
\end{array}\right) \operatorname{var}\left(\widehat{a}_{t}^{r}\right) \\
& \operatorname{var}_{\text {aut }}\left(\widehat{s}_{t}-\widetilde{s}_{t}\right)-\operatorname{var}_{\text {com }}\left(\widehat{s}_{t}-\widetilde{s}_{t}\right)=\left(\frac{\varphi_{\text {aut }}^{2}}{1-\rho_{1, \text { aut }}^{2}} \frac{1+\rho_{1, \text { aut }} \rho_{a}}{1-\rho_{1, \text { aut }} \rho_{a}}-\frac{\varphi_{\text {com }}^{2}}{1-\rho_{1, \text { com }}^{2}} \frac{1+\rho_{1, \text { com }} \rho_{a}}{1-\rho_{1, \text { com }} \rho_{a}}\right) \operatorname{var}\left(\widehat{a}_{t}^{r}\right) \\
& +2 \frac{1+\psi}{1+\lambda^{c} \psi}\left(\frac{\varphi_{\text {com }}}{1-\rho_{1, \text { com }} \rho_{a}}-\frac{\varphi_{\text {aut }}}{1-\rho_{1, \text { aut }} \rho_{a}}\right) \operatorname{var}\left(\widehat{a}_{t}^{r}\right) \\
& \operatorname{var}_{\text {aut }}\left(\widehat{y}_{t}^{r}-\widetilde{y}_{t}^{r}\right)-\operatorname{var}_{\text {com }}\left(\widehat{y}_{t}^{r}-\widetilde{y}_{t}^{r}\right)=\left(\begin{array}{c}
\left(\lambda^{a}\right)^{2} \frac{\varphi_{\text {aut }}^{2}}{1-\rho_{1, a u t}^{2}} \frac{1+\rho_{1, a u t} \rho_{a}}{1-\rho_{1, a u} \rho_{a}} \\
-\left(\lambda^{c}\right)^{2} \frac{\varphi_{\text {com }}^{2}}{1-\rho_{1, \text { com }}^{2}} \frac{1+\rho_{1, \text { com }} \rho_{a}}{1-\rho_{1, c o m} \rho_{a}}
\end{array}\right) \operatorname{var}\left(\widehat{a}_{t}^{r}\right) \\
& +2 \frac{\lambda^{c}(1+\psi)}{1+\lambda^{c} \psi}\left(\frac{\lambda^{c} \varphi_{\text {com }}}{1-\rho_{1, \text { com }} \rho_{a}}-\frac{\lambda^{a} \varphi_{\text {aut }}}{1-\rho_{1, a u t} \rho_{a}}\right) \operatorname{var}\left(\widehat{a}_{t}^{r}\right) \\
& \operatorname{var}_{\text {aut }}\left(\Delta \widehat{s}_{t}\right)-\operatorname{var}_{\text {com }}\left(\Delta \widehat{s}_{t}\right)=2\left(1-\rho_{a}\right)\left(\begin{array}{c}
\frac{1-\rho_{1, a u t}}{1-\rho_{1, a u t} \rho_{a}} \frac{\varphi_{a u t}^{2}}{1-\rho_{1, a u t}^{2}} \\
-\frac{1-\rho_{1, c o m}}{1-\rho_{1, \text { com }} \rho_{a}} \frac{\varphi_{\text {com }}^{2}}{1-\rho_{1, \text { com }}^{2}}
\end{array}\right) \operatorname{var}\left(\widehat{a}_{t}^{r}\right)
\end{aligned}
$$


Now we can deduce that

$$
\begin{aligned}
W_{t}^{\text {aut }}-W_{t}^{\text {com }}= & -(1-2 \mu(1-\alpha))^{2} \operatorname{var}_{\text {aut }}\left(\widehat{s}_{t}\right)-(2 \alpha-1)^{2} \operatorname{var}_{\text {com }}\left(\widehat{s}_{t}\right) \\
& -2(1-2 \alpha) \frac{1+\psi}{1+\lambda^{c} \psi}\left(\frac{(1-2 \alpha) \varphi_{\text {com }}}{1-\rho_{1, \text { com }} \rho_{a}}-\frac{(2 \mu(1-\alpha)-1) \varphi_{\text {aut }}}{1-\rho_{1, a u t} \rho_{a}}\right) \operatorname{var}\left(\widehat{a}_{t}^{r}\right) \\
& -4 \mu \alpha(1-\alpha)\left(\operatorname{var}_{\text {aut }}\left(\widehat{s}_{t}\right)-\operatorname{var}_{\text {com }}\left(\widehat{s}_{t}\right)\right) \\
& -8 \mu \alpha(1-\alpha) \frac{(1+\psi)}{1+\lambda^{c} \psi}\left(\frac{\varphi_{\text {com }}}{1-\rho_{1, \text { com }} \rho_{a}}-\frac{\varphi_{\text {aut }}}{1-\rho_{1, a u t} \rho_{a}}\right) \operatorname{var}\left(\widehat{a}_{t}^{r}\right) \\
& -\psi\left(\left(\lambda^{a}\right)^{2} \operatorname{var}_{a u t}\left(\widehat{s}_{t}\right)-\left(\lambda^{c}\right)^{2} \operatorname{var}_{\text {com }}\left(\widehat{s}_{t}\right)\right) \\
& -2 \psi \frac{\lambda^{c}(1+\psi)}{1+\lambda^{c} \psi}\left(\frac{\lambda^{c} \varphi_{\text {com }}}{1-\rho_{1, \text { com }} \rho_{a}}-\frac{\lambda^{a} \varphi_{a u t}}{1-\rho_{1, a u t} \rho_{a}}\right) \operatorname{var}\left(\widehat{a}_{t}^{r}\right) \\
& -2\left(1-\rho_{a}\right) \theta \kappa^{-1}\left(\frac{\left(1-\rho_{1, a u t}\right)}{\left(1+\rho_{1, a u t} \rho_{a}\right)} \operatorname{var}_{\text {aut }}\left(\widehat{s}_{t}\right)-\frac{\left(1-\rho_{1, \text { com }}\right)}{\left(1+\rho_{1, \text { com }} \rho_{a}\right)} \operatorname{var}_{\text {com }}\left(\widehat{s}_{t}\right)\right) \text { A.84) }
\end{aligned}
$$

or, simplifying further

$$
W_{t}^{a u t}-W_{t}^{\text {com }}=\Xi_{\text {com }} v a r_{c o m}\left(\widehat{s}_{t}\right)-\Xi_{a u t} v a r_{a u t}\left(\widehat{s}_{t}\right)-\Xi_{a u t, \text { com }} \operatorname{var}\left(\widehat{a}_{t}^{r}\right)
$$

where

$$
\begin{aligned}
\Xi_{\text {aut }}= & (1-2 \mu(1-\alpha))^{2}+4 \mu \alpha(1-\alpha)+\psi\left(\lambda^{a}\right)^{2}+2\left(1-\rho_{a}\right) \theta \kappa^{-1} \frac{\left(1-\rho_{1, a u t}\right)}{\left(1+\rho_{1, a u t} \rho_{a}\right)} \\
\Xi_{c o m}= & (2 \alpha-1)^{2}+4 \mu \alpha(1-\alpha)+\psi\left(\lambda^{c}\right)^{2}+2\left(1-\rho_{a}\right) \theta \kappa^{-1} \frac{\left(1-\rho_{1, \text { com }}\right)}{\left(1+\rho_{1, \text { com }} \rho_{a}\right)} \\
\Xi_{a u t, c o m}= & \frac{2(1+\psi)}{1+\lambda^{c} \psi}\left[(1-2 \alpha)\left(\frac{(1-2 \alpha) \varphi_{c o m}}{1-\rho_{1, c o m} \rho_{a}}-\frac{(2 \mu(1-\alpha)-1) \varphi_{a u t}}{1-\rho_{1, a u t} \rho_{a}}\right)\right. \\
& +4 \mu \alpha(1-\alpha)\left(\frac{\varphi_{\text {com }}}{1-\rho_{1, \text { com }} \rho_{a}}-\frac{\varphi_{a u t}}{1-\rho_{1, a u t} \rho_{a}}\right) \\
& \left.+\psi \lambda^{c}\left(\frac{\lambda^{c} \varphi_{\text {com }}}{1-\rho_{1, \text { com }} \rho_{a}}-\frac{\lambda^{a} \varphi_{a u t}}{1-\rho_{1, a u t} \rho_{a}}\right)\right]
\end{aligned}
$$

Finally, using the expression of the variance of terms of trade under alternative financial market structures

$$
W_{t}^{\text {aut }}-W_{t}^{\text {com }}=\left(\Xi_{\text {com }}^{\prime}-\Xi_{\text {aut }}^{\prime}-\Xi_{\text {aut }, \text { com }}\right) \operatorname{var}\left(\widehat{a}_{t}^{r}\right)
$$

where

$$
\Xi_{\text {aut }}^{\prime}=\Xi_{\text {aut }} \frac{\varphi_{\text {aut }}^{2}}{1-\rho_{1, a u t}^{2}} \frac{1+\rho_{1, a u t} \rho_{a}}{1-\rho_{1, a u t} \rho_{a}} \text { and } \Xi_{c o m}^{\prime}=\Xi_{c o m} \frac{\varphi_{\text {com }}^{2}}{1-\rho_{1, \text { com }}^{2}} \frac{1+\rho_{1, c o m} \rho_{a}}{1-\rho_{1, c o m} \rho_{a}}
$$

\section{A.7 The effects of persistence}

Figure 4 reports the difference in welfare expressed as a percentage of steady-state consumption $\mathcal{W}=100\left(E\left(W_{t}^{\text {aut }}\right)-E\left(W_{t}^{\text {com }}\right)\right) /\left(c+c^{*}\right)$ as a function of persistence with a fixed Calvo parameter $(\eta=0.75)$ and a fixed trade elasticity $(\mu=1.5)$.

For intermediate to large values of persistence, the effects on nominal rigidities is stronger and equilibria under complete markets deliver lower levels of welfare than equilibria under financial autarky. Larger values of persistence, implying close-to-permanent shocks, magnify the allocation effect and lead complete markets to produce higher levels of welfare. 
Figure 4: $\mathcal{W}$ as a function of the persistence of productivity shocks.

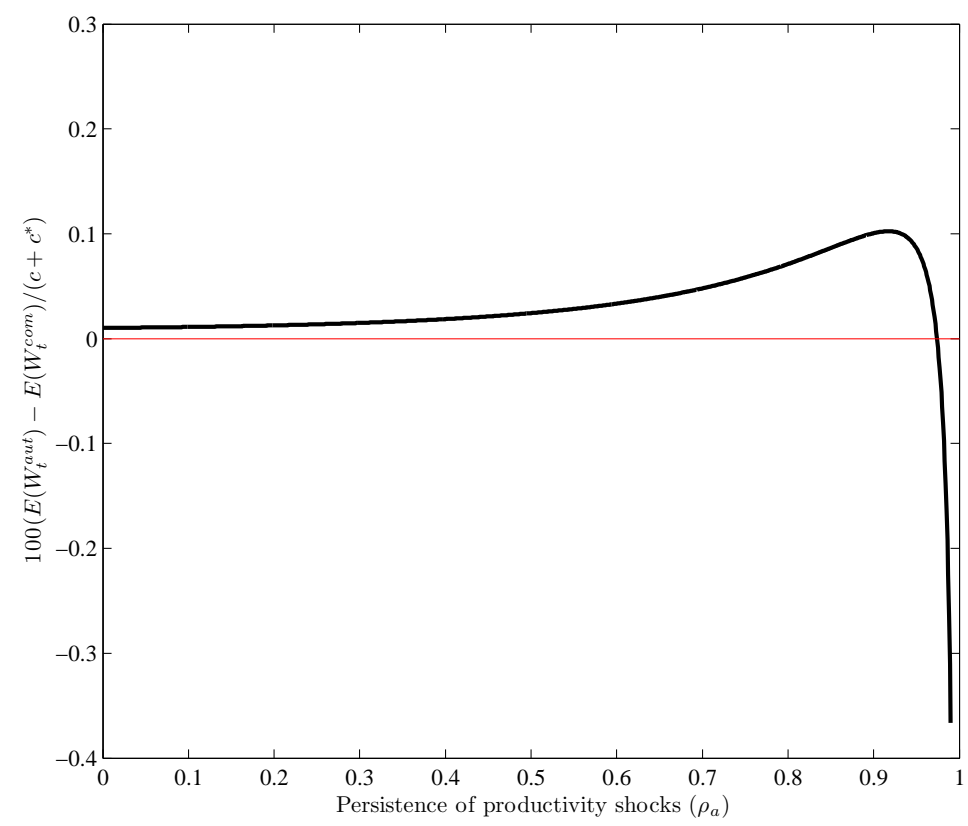

\section{B The medium-scale model}

\section{B.1 Equilibrium conditions}

\section{B.1.1 Households}

We carry over the two-country structure used in Appendix A, but extend the analysis by considering a unit-mass continuum of households in each country. Let us focus on the behavior of household $j$ in the domestic economy that maximizes its lifetime welfare

$$
E_{t}\left\{\sum_{s=t}^{\infty} \beta^{s-t} \epsilon_{b, s}\left(\frac{\left(c_{s}(j)-h_{s}(j)\right)^{1-\sigma_{c}}}{1-\sigma_{c}}-\epsilon_{n, s} \frac{n_{s}(j)^{1+\psi}}{1+\psi}\right)\right\},
$$

where $c_{t}(j)$ denotes consumption, $h_{t}(j)=h_{c} c_{t-1}(j)$ a stock of external consumption habits, $n_{t}(j)$ the hours of work supplied and $\epsilon_{b, t}$ and $\epsilon_{n, t}$ respectively an intertemporal substitution and a labor supply shock following autoregressive processes. The budget constraint of agent $j$ is

$$
\begin{aligned}
r_{t, t+1} b_{t}(j)+p_{t}\left(c_{t}(j)+i_{t}(j)\right) & =b_{t-1}(j)+\left(1-\tau^{w}\right) w_{t}(j) n_{t}(j) \\
& +\left(r_{t}^{k} z_{t}(j)-p_{t} a c_{t}^{z}(j)\right) k_{t-1}(j)+\varphi_{t}(j)-\operatorname{tax}_{t}
\end{aligned}
$$

where $b_{t}(j)$ denotes the nominal value of a portfolio composed of Arrow-Debreu securities at time $t$ producing a state-contingent return $r_{t, t+1}$ between period $t$ and $t+1$. Further, $p_{t}$ is the price index of consumption goods, $p_{h, t}$ the price index of goods produced in the domestic economy, $i_{t}(j)$ is the investment in physical capital, $\tau^{w}$ is the labor income tax rate, introduced to offset monopolistic distortions on the labor market, $w_{t}(j)$ is the nominal wage paid to type- $j$ labor, $r_{t}^{k}$ is the gross return on the capital stock, $z_{t}(j)$ is the utilization rate of capital, $a c_{t}^{z}(j)=\frac{\phi_{z}}{2}\left(z_{t}(j)-1\right)^{2}$ is a capital utilization adjustment cost, $\varphi_{t}(j)$ denotes profits from monopolistic firms and $\operatorname{tax}_{t}$ 
is a lump-sum tax. An additional constraint to this optimization problem is the law of capital accumulation

$$
k_{t}(j)=(1-\delta) k_{t-1}(j)+\epsilon_{i, t}\left(1-a c_{t}^{i}(j)\right) i_{t}(j)
$$

where $\epsilon_{i, t}$ is an investment shock following an autoregressive process, and where

$$
a c_{t}^{i}(j)=\frac{\phi_{i}}{2}\left(\frac{i_{t}(j)}{i_{t-1}(j)}-1\right)^{2}
$$

is an investment adjustment cost. The maximization of the welfare function subject to the budget constraint with respect to consumption yields

$$
\beta E_{t}\left(\frac{r_{t} u_{c, t+1}(j)}{\pi_{t+1} u_{c, t}(j)}\right)=1
$$

where $\pi_{t}=p_{t} / p_{t-1}, r_{t}$ is the nominal return on risk-free one-period bonds, and $u_{c, t}(j)$ is the marginal utility of consumption. Similar conditions hold for the foreign household, and the structure of complete international asset markets yields

$$
\frac{u_{c, t}(j)}{p_{t}}=\frac{u_{c^{*}, t}(j)}{p_{t}^{*}}, \forall t
$$

Under our alternative financial market specification, financial markets are incomplete across countries (but complete within countries) with quadratic portfolio adjustment costs (see SchmittGrohé and Uribe [2003]). As a consequence Euler equations under incomplete markets are

$$
\begin{aligned}
\beta E_{t}\left(\frac{r_{t}}{1+\phi_{b} b_{t}^{r}} \frac{u_{c, t+1}(j)}{\pi_{t+1} u_{c, t}(j)}\right) & =1 \\
\beta E_{t}\left(\frac{r_{t}}{1-\phi_{b}^{*} b_{t}^{r} / \operatorname{rer}_{t}} \frac{u_{c^{*}, t+1}(j)}{\pi_{t+1}^{*} u_{c^{*}, t}(j)}\right) & =1
\end{aligned}
$$

where $b_{t}^{r}$ denotes the domestic real net foreign assets, assumed to be zero in the steady state, $\phi_{b}$ controls the magnitude of portfolio costs and $r e r_{t}=p_{t}^{*} / p_{t}$ is the real exchange rate. We consider a similar structure for consumption and investment goods. Keeping notations unchanged with respect to Appendix A, we get the following domestic and foreign good demands

$$
\begin{aligned}
& x_{h, t}(j)=(1-\alpha)\left(\frac{p_{h, t}}{p_{t}}\right)^{-\mu} x_{t}(j), x_{f, t}(j)=\alpha\left(\frac{p_{f, t}}{p_{t}}\right)^{-\mu} x_{t}(j) \\
& x_{f, t}^{*}(j)=(1-\alpha)\left(\frac{p_{f, t}}{p_{t}^{*}}\right)^{-\mu} x_{t}^{*}(j), x_{h, t}^{*}(j)=\alpha\left(\frac{p_{h, t}}{p_{t}^{*}}\right)^{-\mu} x_{t}^{*}(j)
\end{aligned}
$$

for $x=\left\{c, i, a c^{z}\right\}$, where $p_{h, t}$ and $p_{f, t}$ are the prices of goods produced respectively in the domestic and in the foreign economy, and $\mu$ is the trade elasticity. The wage-setting equation is derived using the aggregate labor bundle used by firms

$$
n_{t}(\omega)=\left(\int_{0}^{1} n_{t}(j, \omega)^{\frac{\theta_{t}^{w}-1}{\theta_{t}^{w}}} d j\right)^{\frac{\theta_{t}^{w}}{\theta_{t}^{w}-1}} \text { with }\left(\theta_{t}^{w}-1\right)^{-1}=\left(\theta_{t}^{w}-1\right)^{-1}+\sigma_{w} \xi_{w, t}
$$

where $\xi_{w, t}$ is a wage mark-up shock, to derive optimal labor demands

$$
n_{t}(j, \omega)=\left(\frac{w_{t}(j)}{w_{t}}\right)^{-\theta_{t}^{w}} n_{t}(\omega)
$$


These labor demands are taken into account by monopolistic wage-setters in addition to their budget constraint when solving their optimization program. Further, we assume sticky wages whereby wage-setters face an individual probability $1-\eta^{w}$ to be allowed to re-optimize and a probability $\eta^{w}$ to index their previous period wage on lagged CPI inflation, where $\gamma^{w}$ is the degree of wage indexation. The corresponding optimal wage $w_{t}(j)$ is ${ }^{20}$

$$
\sum_{i=0}^{\infty}\left(\beta \eta^{w}\right)^{i} E_{t}\left(n_{t+i}(j)\left(\frac{\theta_{t+i}^{w}}{\theta_{t+i}^{w}-1} \frac{u_{n, t+i}}{u_{c, t+i}}+\left(1-\tau^{w}\right) \frac{\mathrm{w}_{t}(j)}{p_{t+i}}\left(\frac{p_{t+i-1}}{p_{t-1}}\right)^{\gamma^{w}}\right)\right)=0
$$

and the dynamics of wages is

$$
w_{t}^{1-\theta_{t}^{w}}=\eta^{w}\left(w_{t-1} \pi_{t-1}^{\gamma^{w}}\right)^{1-\theta_{t}^{w}}+\left(1-\eta^{w}\right) \mathrm{w}_{t}(j)^{1-\theta_{t}^{w}}
$$

From now on we assume perfect risk-sharing among households of the domestic economy. Households $j$ are thus identical and we drop the $j$ indices. Defining $q_{t} p_{t} \lambda_{t}$ as the Lagrange multiplier associated with the capital accumulation constraint, first-order conditions with respect to the capital stock, investment, and the utilization rate, are respectively

$$
\begin{aligned}
\beta E_{t}\left(\frac{u_{c, t+1}}{u_{c, t}}\left(q_{t+1}(1-\delta)+\left(\frac{r_{t+1}^{k}}{p_{t+1}} z_{t+1}-\frac{\phi_{z}}{2}\left(z_{t+1}-1\right)^{2}\right)\right)\right) & =q_{t} \\
q_{t} \epsilon_{i, t}\left(1-\frac{\phi_{i}}{2} d_{t}^{2}-\phi_{i} d_{t}\left(1+d_{t}\right)\right)+\beta E_{t}\left(\frac{u_{c, t+1}}{u_{c, t}} q_{t+1} \epsilon_{i, t+1} \phi_{i} d_{t+1}\left(1+d_{t+1}\right)^{2}\right) & =1 \\
\frac{r_{t}^{k}}{p_{t}}-\phi_{z}\left(z_{t}-1\right) & =0
\end{aligned}
$$

where $d_{t}=\frac{i_{t}}{i_{t-1}}-1$.

\section{B.1.2 Firms}

There is a continuum of final good producers indexed in $\omega$ in each country, with the following production function

$$
y_{t}(\omega)=\epsilon_{a, t} k_{t}^{s}(\omega)^{\iota} \ell_{t}(\omega)^{1-\iota}
$$

where $k_{t}^{s}$ is a measure of capital services used in production and $\epsilon_{a, t}$ is a productivity measure following an autoregressive process. Cost minimization implies

$$
k_{t}^{s}(\omega)=\frac{\iota}{1-\iota} \frac{w_{t}}{r_{t}^{k}} \ell_{t}(\omega)
$$

which can be used to derive an expression of the nominal marginal cost

$$
m c_{t}(\omega)=m c_{t}=\left(\epsilon_{a, t}\right)^{-1}\left(r_{t}^{k}\right)^{\iota}\left(w_{t}\right)^{1-\iota} \iota^{-\iota}(1-\iota)^{-(1-\iota)}
$$

\footnotetext{
${ }^{20} \mathrm{~A}$ similar condition holds for foreign households:

$$
\sum_{i=0}^{\infty}\left(\beta \eta^{w *}\right)^{i} E_{t}\left(n_{t+i}^{*}(j)\left(\frac{\theta_{t+i}^{w *}}{\theta_{t+i}^{w *}-1} \frac{u_{n^{*}, t+i}}{u_{c^{*}, t+i}}+\left(1-\tau^{w}\right) \frac{\mathrm{w}_{t}^{*}(j)}{p_{t+i}^{*}}\left(\frac{p_{t+i-1}^{*}}{p_{t-1}^{*}}\right)^{\gamma^{w *}}\right)\right)=0
$$
}


The adjustment of production prices is also subject to Calvo contracts with partial indexation. Re-setters face the following problem

$$
\max _{\mathbf{p}_{h, t}(\omega)} \sum_{i=0}^{\infty}\left(\beta \eta^{p}\right)^{i} E_{t}\left(\frac{u_{c, t+i}}{u_{c, t}} \frac{p_{t}}{p_{t+i}}\left(\left(1-\tau^{p}\right) \mathrm{p}_{h, t}(\omega)\left(\frac{p_{h, t+i-1}}{p_{h, t-1}}\right)^{\gamma^{p}} y_{t+i}(\omega)-m c_{t+i} y_{t+i}(\omega)\right)\right)
$$

where $\tau^{p}$ is the tax rate on sales, taking into account the demand addressed to firm $\omega$

$$
y_{t}(\omega)=\left(\frac{p_{h, t}(\omega)}{p_{h, t}}\right)^{-\theta_{t}^{p}} y_{t}
$$

where the mark-up evolves according to

$$
\left(\theta_{t}^{p}-1\right)^{-1}=\left(\theta^{p}-1\right)^{-1}+\sigma_{p} \xi_{p, t}
$$

The optimal pricing condition is thus

$$
\sum_{i=0}^{\infty}\left(\beta \eta^{p}\right)^{i} E_{t}\left(\frac{u_{c, t+i}}{p_{t+i}} y_{t+i}(\omega)\left(\left(1-\tau^{p}\right) \mathrm{p}_{h, t}(\omega)\left(\frac{p_{h, t+i-1}}{p_{h, t-1}}\right)^{\gamma^{p}}-\frac{\theta_{t+i}^{p}}{\theta_{t+i}^{p}-1} m c_{t+i}\right)\right)=0
$$

while the dynamics of prices is given by

$$
p_{h, t}^{1-\theta_{t}^{p}}=\eta^{p}\left(p_{h, t-1} \pi_{h, t-1}^{\gamma^{p}}\right)^{1-\theta_{t}^{p}}+\left(1-\eta^{p}\right) \mathrm{p}_{h, t}(\omega)^{1-\theta_{t}^{p}}
$$

\section{B.1.3 Monetary policy, government and aggregation}

As in Smets and Wouters [2003], it is assumed that the central bank of the monetary union commits to the following interest rate rule

$$
\frac{r_{t}}{r}=\left(\frac{r_{t-1}}{r}\right)^{d_{r}}\left(\left(\frac{\pi_{t}^{u}}{\epsilon_{\pi, t}}\right)^{d_{\pi}}\left(\frac{y_{t}^{u}}{\widetilde{y}_{t}^{u}}\right)^{d_{y}}\right)^{1-d_{r}}\left(\frac{\pi_{t}^{u}}{\pi_{t-1}^{u}}\right)^{d_{\Delta \pi}}\left(\frac{y_{t}^{u} / y_{t-1}^{u}}{\widetilde{y}_{t}^{u} / \widetilde{y}_{t-1}^{u}}\right)^{d_{\Delta y}} \exp \left(\sigma_{r} \xi_{r, t}\right)
$$

where $\pi_{t}^{u}$ is the union-wide inflation rate, $y_{t}^{u}$ is the union-wide output, $\widetilde{y}_{t}^{u}$ its flexible prices counterpart and $\epsilon_{\pi, t}$ and $\xi_{r, t}$ respectively an inflation-target and a monetary policy shock. Government budget constraints are

$$
\begin{aligned}
\operatorname{tax}_{t}+\tau^{p} \int_{0}^{1} p_{h, t}(\omega) y_{t}(\omega)+\tau^{w} \int_{0}^{1} w_{t}(j) n_{t}(j) & =g_{t} \\
\operatorname{tax}_{t}^{*}+\tau^{p *} \int_{0}^{1} p_{f, t}(\omega) y_{t}^{*}(\omega)+\tau^{w *} \int_{0}^{1} w_{t}^{*}(j) n_{t}^{*}(j) & =g_{t}^{*}
\end{aligned}
$$

where $g_{t}=g \epsilon_{g, t}$ and $g_{t}^{*}=g^{*} \epsilon_{g, t}^{*}$ and $\epsilon_{g, t}$ and $\epsilon_{g, t}^{*}$ follow autoregressive processes. Equilibrium in the labor markets implies

$$
\begin{aligned}
& \ell_{t}=\int_{0}^{1} \ell_{t}(\omega) d \omega=\int_{0}^{1} \int_{0}^{1} n_{t}(j, \omega) d j d \omega=\Upsilon_{t}^{w} n_{t} \\
& \ell_{t}^{*}=\int_{0}^{1} \ell_{t}^{*}(\omega) d \omega=\int_{0}^{1} \int_{0}^{1} n_{t}^{*}(j, \omega) d j d \omega=\Upsilon_{t}^{w *} n_{t}^{*}
\end{aligned}
$$


where $\Upsilon_{t}^{w}=\int_{0}^{1}\left(\frac{w_{t}(j)}{w_{t}}\right)^{-\theta_{t}^{w}} d j$ and $\Upsilon_{t}^{w *}=\int_{0}^{1}\left(\frac{w_{t}^{*}(j)}{w_{t}^{*}}\right)^{-\theta_{t}^{w *}} d j$ denote the dispersion of wages. Equilibrium in the physical capital market gives

$$
\begin{aligned}
k_{t}^{s} & =\int_{0}^{1} k_{t}^{s}(\omega) d \omega=\int_{0}^{1} z_{t}(j) k_{t-1}(j) d j=z_{t} k_{t-1} \\
k_{t}^{s *} & =\int_{0}^{1} k_{t}^{s *}(\omega) d \omega=\int_{0}^{1} z_{t}^{*}(j) k_{t-1}^{*}(j) d j=z_{t}^{*} k_{t-1}^{*}
\end{aligned}
$$

while equilibrium in goods markets yields

$$
\begin{aligned}
& y_{t}=(1-\alpha)\left(\frac{p_{h, t}}{p_{t}}\right)^{-\mu}\left(c_{t}+i_{t}+a c_{t}^{z} k_{t-1}\right)+\alpha\left(\frac{p_{h, t}}{p_{t}^{*}}\right)^{-\mu}\left(c_{t}^{*}+i_{t}^{*}+a c_{t}^{z *} k_{t-1}^{*}\right)+g_{t} \\
& y_{t}^{*}=(1-\alpha)\left(\frac{p_{f, t}}{p_{t}^{*}}\right)^{-\mu}\left(c_{t}^{*}+i_{t}^{*}+a c_{t}^{z *} k_{t-1}^{*}\right)+\alpha\left(\frac{p_{f, t}}{p_{t}}\right)^{-\mu}\left(c_{t}+i_{t}+a c_{t}^{z} k_{t-1}\right)+g_{t}^{*}
\end{aligned}
$$

Finally, using other aggregate conditions, aggregate production functions are

$$
\begin{aligned}
\Upsilon_{t}^{p} y_{t} & =\epsilon_{a, t}\left(z_{t} k_{t-1}\right)^{\iota}\left(\Upsilon_{t}^{w} n_{t}\right)^{1-\iota} \\
\Upsilon_{t}^{p *} y_{t}^{*} & =\epsilon_{a, t}^{*}\left(z_{t}^{*} k_{t-1}^{*}\right)^{\iota^{*}}\left(\Upsilon_{t}^{w *} n_{t}^{*}\right)^{1-\iota^{*}}
\end{aligned}
$$

where $\Upsilon_{t}^{p}=\int_{0}^{1}\left(\frac{p_{h, t}(\omega)}{p_{h, t}}\right)^{-\theta_{t}^{p}} d \omega$ and $\Upsilon_{t}^{p *}=\int_{0}^{1}\left(\frac{p_{f, t}(\omega)}{p_{f, t}}\right)^{-\theta_{t}^{p *}} d \omega$ denote the dispersion of producer prices.

\section{B.2 Steady state}

We analyze the dynamics of the model around a symmetric steady state implying $s=r e r=1$, as well as $b^{r}=0$. Therefore equilibria under alternative financial market structures share the same steady state. Further, in the steady state, by definition, $d=0$, and the dynamics of $q$ gives $q=1$. The condition on the utilization rate thus gives

$$
r^{k}=\phi_{z}(z-1)
$$

which plugged in the investment equation pins down $z$

$$
z=\sqrt{1+\frac{2\left(\beta^{-1}+\delta-1\right)}{\phi_{z}}}
$$

as well as $r^{k}$. Next use the real marginal cost to get the real wage $w$

$$
w=\left(\frac{\left(\theta^{p}-1\right)\left(1-\tau^{p}\right)}{\theta^{p}} \iota^{\iota}(1-\iota)^{(1-\iota)}\left(r^{k}\right)^{-\iota}\right)^{\frac{1}{1-\iota}}
$$

Further, use

$$
k=\frac{\iota}{1-\iota} \frac{w}{r^{k}} \frac{n}{z}
$$

and the aggregate production function

$$
y=(z k)^{\iota} n^{1-\iota}
$$


to express the goods market clearing condition as a function of hours and consumption only

$$
\Psi n=c
$$

where $\Psi=(1-\varrho)\left(\frac{\iota}{1-\iota} \frac{w}{r^{k} z}\right)^{\iota}-\left(\delta+a c^{z}\right) \frac{\iota}{1-\iota} \frac{w}{r^{k} z}$, and where $\varrho=g / y$ is the steady-state share of public expenditure in GDP. We finally constrain $\epsilon_{n}$ to get $n=1$, which gives

$$
c=\Psi
$$

and pins down consumption, as well as all remaining variables. Using the wage equation, the constraint on $\epsilon_{n}$ writes

$$
\epsilon_{n}=\frac{\left(\theta^{w}-1\right)\left(1-\tau^{w}\right)}{\theta^{w}} \frac{w}{\left(\left(1-h_{c}\right) c\right)^{\sigma_{c}}}
$$




\section{B.3 Parameter values}

Table 3: Parameter values

\begin{tabular}{lr}
\hline \hline Discount factor & $\beta=0.99$ \\
Inverse of the Frisch elasticity & $\psi=1.265$ \\
Habit in consumption & $h_{c}=0.551$ \\
Risk-aversion & $\sigma_{c}=1.613$ \\
Trade openness & $\alpha=0.2$ \\
Trade elasticity & $\mu=1.5$ \\
Share of public expenditure in GDP & $\varrho=0.22$ \\
Capital depreciation & $\delta=0.025$ \\
Investment adjustment cost & $\phi_{i}=6.048$ \\
Utilization adjustment cost & $\phi_{z}=0.175$ \\
Capital share & $\iota=0.3$ \\
Steady-state wage mark-up & $\left.\theta^{w}-1\right)^{-1}=0.5$ \\
Steady-state price mark-up & $\left(\theta^{w}-1\right)^{-1}=0.5$ \\
Calvo parameter (wages) & $\eta^{w}=0.756$ \\
Calvo parameter (prices) & $\eta^{p}=0.909$ \\
Indexation (wages) & $\gamma^{w}=0.655$ \\
Indexation (prices) & $\gamma^{p}=0.429$ \\
MP response to lagged interest rate & $d_{r}=0.928$ \\
MP response to inflation & $d_{\pi}=1.668$ \\
MP response to inflation growth & $\Delta^{2}=0.222$ \\
MP response to output gap & $d_{y}=0.144$ \\
MP response to output gap growth & $d_{\Delta y}=0.174$ \\
Pers. of preference shock & $\rho_{b}=0.882$ \\
Pers. of investment shock & $\rho_{i}=0.914$ \\
Pers. of labor supply shock & $\rho_{n}=0.952$ \\
Pers. of productivity shock & $\rho_{a}=0.822$ \\
Pers. of public spending shock & $\rho_{g}=0.952$ \\
Pers. of inflation target shock & $\rho_{\pi}=0.847$ \\
Sd of preference shock & $\sigma_{b}=0.324$ \\
Sd of investment shock & $\sigma_{i}=0.14$ \\
Sd of labor supply shock & $\sigma_{n}=1.709$ \\
Sd of productivity shock & $\sigma_{a}=0.628$ \\
Sd of public spending shock & $\sigma_{g}=0.331$ \\
Sd of inflation target shock & $\sigma_{\pi}=0.028$ \\
Sd of wage mark-up shock & $\sigma_{w}=0.286$ \\
Sd of price mark-up shock & $\sigma_{p}=0.163$ \\
Sd of monetary policy shock & $\sigma_{r}=0.129$ \\
\hline \hline & \\
&
\end{tabular}




\section{B.4 Variance decomposition}

Table 4 presents the variance decomposition of key variables in model III after removing the share of variance explained by monetary and inflation target shocks, as the latter do not affect relative variables and have symmetric effects on both countries.

Table 4: Variance decomposition of the medium-scale model in model III (no capital, no consumption habits, no indexation)

\begin{tabular}{|c|c|c|c|c|c|c|c|c|}
\hline \multirow[b]{4}{*}{$y_{t}$} & \multicolumn{4}{|c|}{ All shocks } & \multicolumn{4}{|c|}{ No Preference shocks } \\
\hline & Prod. & Pref. & Pub. & Mk-up & Prod. & Pre & Pub. & Mk-up \\
\hline & \multicolumn{4}{|c|}{ Complete markets } & \multicolumn{4}{|c|}{ Complete markets } \\
\hline & 4.23 & 94.37 & 1.39 & 0.00 & 75.20 & - & 24.78 & 0.02 \\
\hline$c_{t}$ & 4.61 & 95.13 & 0.26 & 0.00 & 94.61 & - & 5.36 & 0.03 \\
\hline$n_{t}$ & 27.31 & 71.63 & 1.06 & 0.00 & 96.27 & - & 3.73 & 0.00 \\
\hline$\pi_{i, t}$ & 16.83 & 82.93 & 0.23 & 0.01 & 98.59 & - & 1.36 & 0.04 \\
\hline$s_{t}$ & 3.72 & 96.00 & 0.28 & 0.00 & 93.09 & - & 6.91 & 0.01 \\
\hline \multirow[t]{2}{*}{$W_{t}$} & 1.78 & 97.36 & 0.87 & 0.00 & 67.21 & - & 32.79 & 0.00 \\
\hline & \multicolumn{4}{|c|}{ Incomplete markets } & \multicolumn{4}{|c|}{ Incomplete markets } \\
\hline$y_{t}$ & 4.68 & 93.74 & 1.57 & 0.00 & 74.83 & - & 25.16 & 0.02 \\
\hline$c_{t}$ & 4.38 & 95.36 & 0.27 & 0.00 & 94.22 & - & 5.75 & 0.03 \\
\hline$n_{t}$ & 29.32 & 69.51 & 1.17 & 0.00 & 96.17 & - & 3.83 & 0.00 \\
\hline$\pi_{i, t}$ & 18.34 & 81.43 & 0.23 & 0.01 & 98.72 & - & 1.23 & 0.05 \\
\hline$s_{t}$ & 5.31 & 94.42 & 0.27 & 0.00 & 95.15 & - & 4.85 & 0.01 \\
\hline$W_{t}$ & 1.17 & 97.36 & 0.87 & 0.00 & 67.21 & - & 32.79 & 0.00 \\
\hline
\end{tabular}

The contribution of monetary policy and inflation target shocks has been removed. The contribution of investment shocks is null given the absence of capital accumulation in model III. 